\title{
Photochemical production of aerosols from real plant emissions
}

\author{
Th. F. Mentel ${ }^{1}$, J. Wildt ${ }^{2}$, A. Kiendler-Scharr ${ }^{1}$, E. Kleist ${ }^{2}$, R. Tillmann ${ }^{1}$, M. Dal Maso ${ }^{1}$, R. Fisseha ${ }^{1}$, Th. Hohaus ${ }^{1}$, \\ H. Spahn ${ }^{1}$, R. Uerlings ${ }^{2}$, R. Wegener ${ }^{1}$, P. T. Griffiths ${ }^{3}$, E. Dinar ${ }^{4}$, Y. Rudich ${ }^{4}$, and A. Wahner ${ }^{1}$ \\ ${ }^{1}$ Inst. for Chemistry and Dynamics of the Geosphere, Inst. 2: Troposphere, Research Centre Jülich, 52425 Jülich, Germany \\ ${ }^{2}$ Inst. for Chemistry and Dynamics of the Geosphere, Inst. 3: Phytosphere, Research Centre Jülich, 52425 Jülich, Germany \\ ${ }^{3}$ Centre for Atmospheric Science, Dept. of Chemistry, Lensfield Road, Univ. of Cambridge, Cambridge, CB2 1EW, UK \\ ${ }^{4}$ Dept. of Environmental Sciences, Weizmann Institute, Rehovot 76100, Israel
}

Received: 17 November 2008 - Published in Atmos. Chem. Phys. Discuss.: 29 January 2009

Revised: 15 May 2009 - Accepted: 2 June 2009 - Published: 7 July 2009

\begin{abstract}
Emission of biogenic volatile organic compounds (VOC) which on oxidation form secondary organic aerosols (SOA) can couple the vegetation with the atmosphere and climate. Particle formation from tree emissions was investigated in a new setup: a plant chamber coupled to a reaction chamber for oxidizing the plant emissions and for forming SOA. Emissions from the boreal tree species birch, pine, and spruce were studied. In addition, $\alpha$-pinene was used as reference compound. Under the employed experimental conditions, $\mathrm{OH}$ radicals were essential for inducing new particle formation, although $\mathrm{O}_{3}(\leq 80 \mathrm{ppb})$ was always present and a fraction of the monoterpenes and the sesquiterpenes reacted with ozone before $\mathrm{OH}$ was generated. Formation rates of $3 \mathrm{~nm}$ particles were linearly related to the VOC carbon mixing ratios, as were the maximum observed volume and the condensational growth rates. For all trees, the threshold of new particle formation was lower than for $\alpha$-pinene. It was lowest for birch which emitted the largest fraction of oxygenated VOC (OVOC), suggesting that OVOC may play a role in the nucleation process. Incremental mass yields were $\approx 5 \%$ for pine, spruce and $\alpha$-pinene, and $\approx 10 \%$ for birch. $\alpha$ Pinene was a good model compound to describe the yield and the growth of SOA particles from coniferous emissions. The mass fractional yields agreed well with observations for boreal forests. Despite the somewhat enhanced VOC and $\mathrm{OH}$ concentrations our results may be up-scaled to eco-system level. Using the mass fractional yields observed for the tree
\end{abstract}

Correspondence to: Th. F. Mentel (t.mentel@fz-juelich.de) emissions and weighting them with the abundance of the respective trees in boreal forests SOA mass concentration calculations agree within $6 \%$ with field observations. For a future VOC increase of $50 \%$ we predict a particle mass increase due to SOA of $19 \%$ assuming today's mass contribution of pre-existing aerosol and oxidant levels.

\section{Introduction}

Vegetation and climate are possibly coupled through emissions of reactive volatile organic compounds (VOC) from plants (Barth et al., 2005; Kulmala et al., 2004a). The emitted VOC react in the atmosphere and their oxidation products assist in the growth of freshly nucleated particles (usually from sulfuric acid, water, and ammonia) or condense onto existing particles, thus contributing to particle mass and size (Kulmala, 2003; Kulmala et al., 2004b) often forming blue haze sometimes observed over forested areas (Went, 1960). The interaction between vegetation and the climate is not unidirectional. For example, the formed aerosols may cool the climate by nucleating clouds and intercepting solar radiation (Kerminen et al., 2005; Kulmala, 2003). Conversely, under changing climatic conditions, the biological sources of biogenic aerosols may be subjected to environmental stress (heat, drought, pollution etc.), thereby potentially altering the emission strength and character in a yet unknown way. This important biological component of atmospheric aerosol and the coupling between vegetation and climate is among the least studied and understood (compare Kulmala et al., 2004a). 
The boreal forest occupies substantial parts of the Earth's northern latitudes, where climate is also expected to change (Denman et al., 2007). Long term observations over the boreal forest in Finland suggest that monoterpenes (MT) and possibly sesquiterpenes (SQT) contribute to formation and growth of new particles (Bonn et al., 2008, Laaksonen et al., 2008) besides sulfuric acid (Kulmala et al., 2006). The potential of MT and SQT as precursors for secondary organic aerosol (SOA) formation has been intensively studied in laboratory and simulation chamber studies with $\mathrm{OH}$ radicals and ozone as oxidants (e.g. see a recent review by Kroll and Seinfeld, 2008 and references therein). However, most of these studies were performed with elevated concentrations of single precursor compounds (mostly $\alpha$-pinene), compared to the mixing ratios of MT and SQT measured near the canopy (Haapanala et al., 2007; Kuhn et al., 2007; Spirig et al., 2005). Oxidant levels were also often higher than in the natural atmosphere

Besides MT and SQT other biogenic VOC are also emitted from vegetation, among these are short chained oxygenated VOC such as methanol or acetone (Folkers et al., 2008; Seco et al., 2007). Such short chained VOC are believed to be of minor importance for particle formation (Carrasco et al., 2007), because their reaction products have too high vapour pressures, unless they are able to form oligomeric structures similar to those formed by glyoxal or methylglyoxal (Fu et al., 2008; Healy et al., 2008; Volkamer et al., 2006). In addition, alcohols and aldehydes containing 6 carbon atoms (wound-induced VOC or products from lipoxygenase activity, e.g. Croft et al., 1993; Heiden et al., 2003), long chained saturated aldehydes (e.g. Ciccioli et al., 1993; Wildt et al., 2003) or aromatic compounds like methyl salicylate (Heiden et al., 1999) are also emitted from plants. However, most of these emissions are stress-induced and strongly depend on the physiological state of the plants. Depending on the plant species and on the physiological state, the stressinduced emission strengths can exceed those of basal monoand sesquiterpenes (e.g. Heiden et al., 2003). However, there is limited information about the role of such compounds in aerosol formation.

Atmospheric oxidation of such biogenic compounds contributes to formation of SOA. But, the high diversity of these VOC does not allow for the investigation of their individual impact on aerosol formation. Nevertheless, to better understand and quantify possible feedback effects between climate, air chemistry, and the biosphere, the impact of all compounds on particle formation should be known. To obtain more realistic emission scenarios in laboratory environments it is advantageous to directly use plants as the source for aerosol precursors. Such experiments better reflect important aspects of the large diversity of compounds in the highly mixed atmosphere than experiments with individual compounds.

Direct plant emissions were already used to investigate particle formation. In order to elucidate the new particle formation in coastal areas McFiggans et al. (2004) generated particles by oxidizing emissions from macro-algae at elevated ozone levels. Joutsensaari and coworkers studied particle formation using VOC emissions from white cabbage exposed to methyl jasmonate and directly adding elevated ozone levels (Joutsensaari et al., 2005; Pinto et al., 2007). Particle formation rates similar to rates observed during atmospheric nucleation events where observed, but with higher growth rates. Joutsensaari et al. (2005) concluded that the condensing species do not significantly contribute to nucleation in the atmosphere and that stress-induced plant emissions may be important for new particle formation. However, because of the high ozone levels (which can also induce stress and cause enhanced VOC emissions) there was a certain difficulty in interpreting the direct stress-induced effect due to the impact of the added methyl jasmonate on particle formation.

Van Reken et al. (2006) investigated particle formation from ozonolysis of holm oak and loblolly pine emissions. To circumvent possible interferences, they separated VOC emissions and the oxidation chamber by housing the plant in a "biogenic emission enclosure" and transferring the emitted VOC into a second, dark reactor, where ozonolysis and subsequent particle formation took place. The VOC concentrations were several ppb and ozone levels were around $50 \mathrm{ppb}$. Particle formation from holm oak and loblolly pine emissions was compared to that obtained in a control experiment with $\alpha$-pinene ( $6 \mathrm{ppb}$ ). Van Reken et al. (2006) found that holm oak emissions were a less efficient particle source, whereas emissions from loblolly pine were more efficient than $\alpha$-pinene. However, simple relations between emission pattern and stress were not evident.

Besides the VOC emissions and sulfuric acid (Hoppel et al., 2001), the physico-chemical conditions of the atmosphere (RH and T) impact particle formation (Bonn and Moortgat, 2002; Cocker et al., 2001; Pathak et al., 2007b; Saathoff et al., 2008; Tillmann et al., 2009). To understand both impacts, the influence of the physico-chemical conditions and the plant emissions must be studied independent of each other. This requires separation between plant chamber and reaction chamber. Here we used a new experimental setup that fulfills this requirement and balances between the environmental complexity and controlled conditions. Similar to the Van Reken et al. (2006) experiments, we coupled two chambers. Air from a chamber containing single or several plants ("plant chamber") is transferred to an empty reaction chamber. The plants are kept under well defined temperature, photosynthetic photon flux density (PPFD), and relative humidity conditions, which could be varied independently of each other allowing for variation of strengths and patterns of VOC emissions without changing other physico-chemical properties of particle formation that takes place in a separate reaction chamber. Variations of the conditions in the reaction chamber such as temperature or humidity allows studying the physico-chemical characteristics of particle formation from a 
given VOC mixture. Holding the conditions in the reaction chamber constant while varying the conditions in the plant chamber allows investigation of the impact of the mixture composition on particle formation without interference with particle formation itself.

Here we focus on the impact of VOC mixtures emitted from trees on particle formation. Maintaining constant conditions in the reaction chamber is prerequisite for comparison of aerosols formed from different mixtures. As a first case study, we investigated particle formation from emissions from pine, birch and spruce which are common species in the boreal forests. As a benchmark, similar experiments were conducted by directly injecting $\alpha$-pinene, the best studied standard for such experiments, from a diffusion source. The goal of this study was to relate emission strength and pattern to particle formation and particle yield and to compare aerosol formation from complex plant emission with that from $\alpha$-pinene.

Although MT react rapidly with ozone, their major loss pathway in the troposphere is by $\mathrm{OH}$ oxidation. We therefore used $\mathrm{OH}$ radicals in addition to $\mathrm{O}_{3}$ allowing a better simulation of the atmosphere where nucleation events are normally coupled to photo-chemical activity (Boy et al., 2005; Kulmala et al., 2004b). To the best of our knowledge this is the first simulation of photo-chemical particle formation from complex plant emissions under such controlled conditions.

\section{Experimental}

\subsection{General description of the experimental setup}

Experiments were carried out in the plant chamber facility at Forschungszentrum Jülich, Germany (Jülich Plant Aerosol Atmosphere Chamber, JPAC). A simplified schematic presentation of the system setup is shown in Fig. 1. The facility consists of three Borosilicate glass chambers $(164 \mathrm{~L}, 1150 \mathrm{~L}$, and $1450 \mathrm{~L}$ ) with Teflon floors. Each chamber is mounted in a separate climate-controlled housing $\left(10\right.$ to $50^{\circ} \mathrm{C}$ with a stability of $\pm 0.5^{\circ} \mathrm{C}$ ). The chambers operate as continuously stirred tank reactors (CSTR) with Teflon fans providing homogeneous mixing. Typical mixing times in the CSTR were about two minutes in all chambers. Either one of the two smaller chambers was used as plant chamber $(164 \mathrm{~L}$ or $1150 \mathrm{~L}$, depending on the size of the investigated plant) followed by the large chamber which served as reaction chamber $(1450 \mathrm{~L})$. Residence times of the air in the plant chambers were 5 to $20 \mathrm{~min}$ and $65 \mathrm{~min}$ in the reaction chamber.

Air was purified by an adsorption dryer (KEA 70; Zander Aufbereitungstechnik GmbH \& Co. KG, Essen, Germany). In addition VOC at the inlet of the plant chamber were destroyed by a palladium catalyst at $450^{\circ} \mathrm{C}$ to below the detection limit of the GC-MS instruments (less than $1 \mathrm{ppt}$ ). Ozone, $\mathrm{NO}$, and $\mathrm{NO}_{2}$ were removed after passing the purification

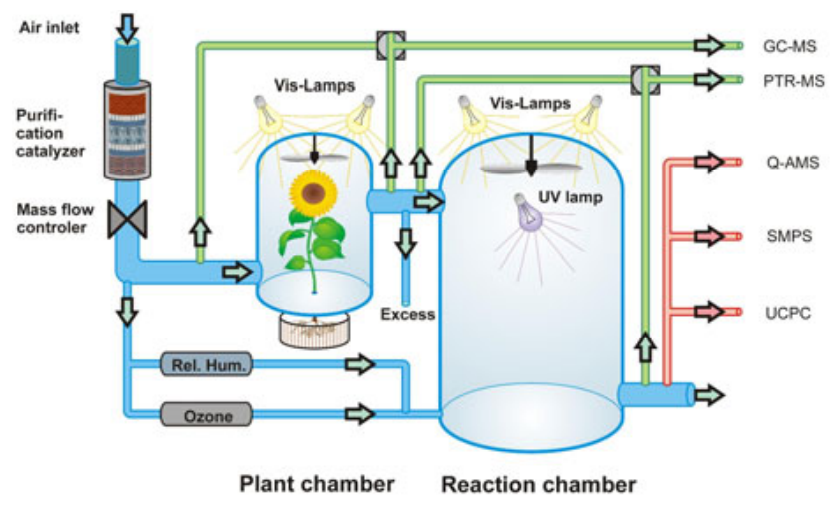

Fig. 1. Plant chamber setup: the chamber housing the plant is coupled to the reaction chamber, where the plant emitted VOC were oxidized by $\mathrm{OH}$ and $\mathrm{O}_{3}$ and particles were formed. Analytical instruments monitored the flow in and out of the chambers. Aerosol instruments sample the air at the outlet of the reaction chamber. Two supply streams were used to maintain stable $\mathrm{RH}$ and $\mathrm{O}_{3}$ mixing ratio in the reaction chamber.

system. Concentrations of $\mathrm{CO}_{2}$ and water vapour were also reduced by the adsorption dryer. The $\mathrm{CO}_{2}$ concentration in the plant chamber was kept at levels of about $350 \mathrm{ppm}$ by adding $\mathrm{CO}_{2}$ at the inlet. The dew point in the plant chamber was restricted to a maximum of $15^{\circ} \mathrm{C}$ to avoid condensation in the transfer line.

Discharge lamps (HQI 400 W/D; Osram, Munich, Germany) simulated the solar light spectrum. At full illumination and at typical mid-canopy heights, photosynthetic photon flux density (PPFD) was $480 \mu \mathrm{mol} \mathrm{m}{ }^{-2} \mathrm{~s}^{-1}$ in the $1150 \mathrm{~L}$ chamber and $800 \mu \mathrm{mol} \mathrm{m}^{-2} \mathrm{~s}^{-1}$ in the $164 \mathrm{~L}$ chamber. Infrared radiation (between 750 and $1050 \mathrm{~nm}$ ) was blocked by filters (type IR3; Prinz Optics GmbH, Stromberg, Germany). Due to absorption of UV light by the glass walls, the shortest wavelength in the plant chambers was about $350 \mathrm{~nm}$. More details of the setup and the performance of individual chambers are described in previous publications (Schimang et al., 2006; Schuh et al., 1997; Wildt et al., 1997). Here we focus on the properties and the potential of this special setup with coupled chambers.

A portion of the air leaving the plant chamber $\left(\approx 16 \mathrm{~L} \mathrm{~min}^{-1}\right)$ was fed into the reaction chamber also operating as a CSTR. The maximum visible light flux in this chamber (PPFD $\approx 360 \mu \mathrm{mol} \mathrm{m}^{-2} \mathrm{~s}^{-1}$ ) led to a $\mathrm{J}\left(\mathrm{NO}_{2}\right)$ in the range of $10^{-3} \mathrm{~s}^{-1}$. A small portion of the air leaving the plant chamber was directed to the analytic instruments allowing VOC measurements.

Two additional air streams were introduced to the reaction chamber, one for ozone and the second for controlling the relative humidity $(\mathrm{RH})$. The air flow used for humidification $\left(\approx 4.6 \mathrm{~L} \mathrm{~min}^{-1}\right)$ and the air flow used for $\mathrm{O}_{3}$ addition $\left(\approx 1.6 \mathrm{~L} \mathrm{~min}^{-1}\right)$ were controlled by mass flow controllers. By regulating the water vapor, the PPFD-dependent 
transpiration of the plants was compensated and the $\mathrm{RH}$ was kept constant at levels around $65 \%$. RH was $50 \%$ in one case (see below). The ozone inlet was placed opposite to the inlet of air from the plant chamber to prevent immediate nucleation under uncontrolled conditions.

The total air flow through the reaction chamber was regularly determined by measuring the residence time of the air in the reaction chamber using ozone as a tracer. Exponential fit to the changing ozone concentration following switching ozone on/off in the inlet stream yielded the residence time.

$\mathrm{OH}$ radicals were generated by ozone photolysis and subsequent reaction of $\mathrm{O}^{1} \mathrm{D}$ with water. The reaction chamber was equipped with an internal UV lamp (Philips, TUV 40W, $\lambda_{\max }=254 \mathrm{~nm}$ ). A part of this UV lamp was shielded by glass tubes which absorb the UV radiation. Changing the size of the gaps between these glass tubes allowed changing the rate of ozone photolysis $\left(\mathrm{J}\left(\mathrm{O}^{1} \mathrm{D}\right)\right)$ and thus changing the rate of $\mathrm{OH}$ production.

The mixing ratios of VOC in the outlet air of the plant chamber were measured by two GC-MS systems. One system was optimized to measure VOC from $\mathrm{C}_{5}$ to $\mathrm{C}_{20}$ including isoprene, mono- and sesquiterpenes as well as compounds from lipoxygenase activity (LOX products) or methyl salicylate (Heiden et al., 1999). The second GC-MS system quantified the concentrations of short chained oxygenated VOC from methanol up to $\mathrm{C}_{10}$ VOC (Folkers, 2002). Both systems were used for VOC identification and quantification. Calibration of both systems was conducted as described in Heiden et al. (2003).

A Proton Transfer Reaction Mass Spectrometer (PTR-MS, Ionicon) was used to determine the concentrations of VOC (and oxidation products) every $10 \mathrm{~min}$. The PTR-MS was switched continuously between the outlet of the plant chamber and the outlet of the reaction chamber. The actual mixing ratios of VOC emissions in the plant chamber were measured at the outlet of the plant chamber. The reactant concentrations in the reaction chamber were deduced by applying the dilution factor by the ozone and water vapor containing air flows to the VOC at the outlet of the plant chamber. The actual concentrations of oxidation products and non-reacted precursors in the reaction chamber were measured at the outlet of the reaction chamber. The differences in the concentration of the incoming and the remaining VOC reflects the progress of the reactions and can be described by a numerical model for ideal CSTR (see Sect. 2.3.1). The measurements at the outlet of the plant chamber were also used as in-situ inter-calibration with the GC-MS systems.

An Ultrafine Condensation Particle Counter (UCPC, TSI3025A) with a nominal activation diameter of $3 \mathrm{~nm}$ was directly connected to the reaction chamber $(6 \mathrm{~mm}$ straight stainless steel tube, $0.5 \mathrm{~m}$ ). This UCPC was used to count the total number of particles formed in the chamber. The reaction chamber was also equipped with a $12 \mathrm{~mm}$ stainless steel tube connecting other aerosol instruments to the reaction chamber. This line was pumped with a total flow of 12-13 $\mathrm{L} \mathrm{min}^{-1}$. A SMPS (TSI3081+TSI3786) measured the number size distribution between 10 and $500 \mathrm{~nm}$. The obtained size distributions were used to determine particle growth rates and were converted into volume distributions to determine particle volume yields. A Quadrupole Aerosol Mass Spectrometer (Q-AMS) was operated to measure the chemical composition of the aerosols (Aerodyne Research Inc. Jayne et al., 2000). Here only the particle time of flight data of the Q-AMS were used to determine the mean effective SOA density. The analytical equipment used to characterize the gas-phase composition and aerosol number is listed in Table 1.

\subsection{Material and methods}

Experiments were conducted in the following way: three to four years old plants that had been stored outdoors in pots (cylinders with $30 \mathrm{~cm}$ height and $30 \mathrm{~cm}$ diameter) were introduced into the plant chamber. Plants used for the experiments were pine (Pinus sylvestris L., 8 plants together in the $1150 \mathrm{~L}$ chamber), birch (Betula pendula L., 1 plant in the $164 \mathrm{~L}$ chamber), and spruce (Picea abies L., 1 plant in the $164 \mathrm{~L}$ chamber). Measurements started after an adaptation period of one day.

A diurnal cycle was simulated by switching on and off the lamps in the plant chamber (9-10 h darkness, $1 \mathrm{~h}$ twilight, 12 or $13 \mathrm{~h}$ illumination $1 \mathrm{~h}$ twilight). During periods of illumination the chamber temperature increased by 3 to $4 \mathrm{~K}$ compared to the periods of darkness. Both photosynthetic activity during the illumination period and the increased temperature enhanced the VOC emissions.

The reaction chamber was permanently illuminated by the visible light to prevent transient variations of the reactor temperature. Temperature in the reaction chamber was kept constant at $17^{\circ} \mathrm{C}$ and $\mathrm{RH}$ was stabilized around $65 \% \mathrm{RH}$ during periods of new particle formation. For technical reasons during the experiments with spruce the RH had to be adjusted at a lower level of about $50 \%$ at $17^{\circ} \mathrm{C}$. Possible consequences will be discussed in detail later. The birch faced some wound stress on being placed inside the plant chamber. Taking into account the changed VOC patterns as observed with the GCMS systems, the data of the first three days were not considered in the following analysis. Thereafter the birch relaxed but some stress remained as indicated by the emission pattern (probably by biting insects). Additionally the first event day of the spruce experiment may be influenced by stress. Nevertheless we included these data to enhance the data base for this first exploratory study, since these situations described here cover situations and variability often found in nature.

\subsection{Procedures}

We investigated a total of 17 new particle formation events from tree emissions, 6 for birch, 5 for pine and 6 for spruce. In addition 10 experiments with $\alpha$-pinene diffusion 
Table 1. Instrumentation at the Jülich Plant Aerosol Atmosphere Chamber (JPAC). .

\begin{tabular}{|c|c|c|c|}
\hline Quantity & Instrument & Sample port & Comments \\
\hline VOC (MT, SQT) & $\begin{array}{l}\text { GC-MS Agilent (HP } 5890 \text { mit 5972A MSD, } \\
\text { Gerstel TDS-G u. KAS3-Injektor) }\end{array}$ & PC* outlet & $\begin{array}{l}\text { GC systems occasionally } \\
\text { switched to RC outlet }\end{array}$ \\
\hline OVOC & $\begin{array}{l}\text { GC-MS Agilent (HP } 6890 \text { with } 5973 \text { MSD, } \\
\text { Gerstel TDS-G u. KAS4-Injector) }\end{array}$ & PC outlet & Folkers (2003) \\
\hline VOC, oxygenated products & PTR-MS, IONICON & $\begin{array}{l}\text { PC outlet, } \\
\text { RC** outlet }\end{array}$ & Switched every 6 min \\
\hline Particle number & UCPC, TSI 3025A & RC outlet & Cut point $\mathrm{D}_{p}>5 \mathrm{~nm}$ \\
\hline Particle number distribution & SMPS TSI 3080/TSI 3786 & RC outlet & Cut point $\mathrm{D}_{p}>18 \mathrm{~nm}$ \\
\hline Size resolved particle composition & Q-AMS, Aerodyne Research & RC outlet & \\
\hline Particle composition & Teflon Filter & RC outlet & Offline analysis \\
\hline Hygroscopic growth & HTDMA, self built & RC outlet & Only efflorescence curves \\
\hline Droplet activation & CCN counter, DMT & RC outlet & $\begin{array}{l}\text { Total activated fract. } \\
\text { at } 0.2-1.2 \% \text { ss }\end{array}$ \\
\hline $\mathrm{O}_{3}$ & Thermo Environmental Instruments, TE49 & RC outlet & \\
\hline NO & ECO Physics CLD 770 AL ppt & $\mathrm{RC}$ inlet+outlet & \\
\hline $\mathrm{CO}_{2}$ & Emmerson Process Manag., Binos 100 4p & PC inlet+outlet & \\
\hline PPFD & LI-COR LI-189 & $\mathrm{PC}$ & \\
\hline Temperature & PT 100 & $\mathrm{PC}, \mathrm{RC}$ & \\
\hline Temperature & Vaisala PT 100 & $\mathrm{RC}$ & \\
\hline Dew point & Walz, Dew point mirror MTS-MK-1 & PC inlet+outlet & \\
\hline RH & Vaisala & $\begin{array}{l}\mathrm{RC} \text { inlet+outlet } \\
\mathrm{RC} \text { inlet+outlet }\end{array}$ & \\
\hline
\end{tabular}

*PC: plant chamber

${ }^{* *} \mathrm{RC}$ : reaction chamber

source were conducted. The experimental and evaluation procedures are described using a typical set of experiment data obtained for pine (Figs. 2-6). The ozone concentration in the reaction chamber was $\approx 80 \mathrm{ppb}$ when the UV lamp was off. Several VOC emitted by the plants were continuously consumed by reaction with ozone and provided a steady state level of "background" vapors. Switching on the UV light induced $\mathrm{OH}$ formation and a drop of the $\mathrm{O}_{3}$ concentration from $\approx 80 \mathrm{ppb}$ to $\approx 40-50 \mathrm{ppb}$. Several minutes after UV illumination, particle formation bursts were observed and monitored by the UCPC and SMPS. The VOC emission strength was varied from experiment to experiment by changing the temperature in the plant chamber.

\subsubsection{Gas phase observations and modeling}

Plant emissions of the MT $(m / z=137)$ and SQT $(m / z=205)$ precursors were determined by the PTR-MS at the outlet of the plant chamber. Non-reacted precursors were measured at the outlet of the reaction chamber. Figure 2 shows the diurnal variation of MT concentrations emitted from pine as measured with the PTR-MS. During darkness in the plant chamber (19:00 $\mathrm{h}-05: 00 \mathrm{~h})$ the sum of MT mixing ratios in the plant chamber was around $0.8 \mathrm{ppb}$. The dilution by the addition of humid air and ozone to the reaction chamber reduced the concentrations in the reaction chamber by $26 \%$ compared to those observed in the plant chamber in this experiment. Additionally, due to ozonolysis, the MT mixing ratios in the reaction chamber were lower and ranged between 0.3 and $0.4 \mathrm{ppb}$. Together with the onset of twilight the emissions from the plants increased due to their dependence on PPFD and temperature. The emissions stabilized after several hours and remained almost constant at about $2.5 \mathrm{ppb}$ in the plant chamber while illuminated. The MT concentrations in the reaction chamber increased in parallel to concentrations in the plant chamber but they reached only about $1.2 \mathrm{ppb}$. This lower increase was due to MT consumption by 


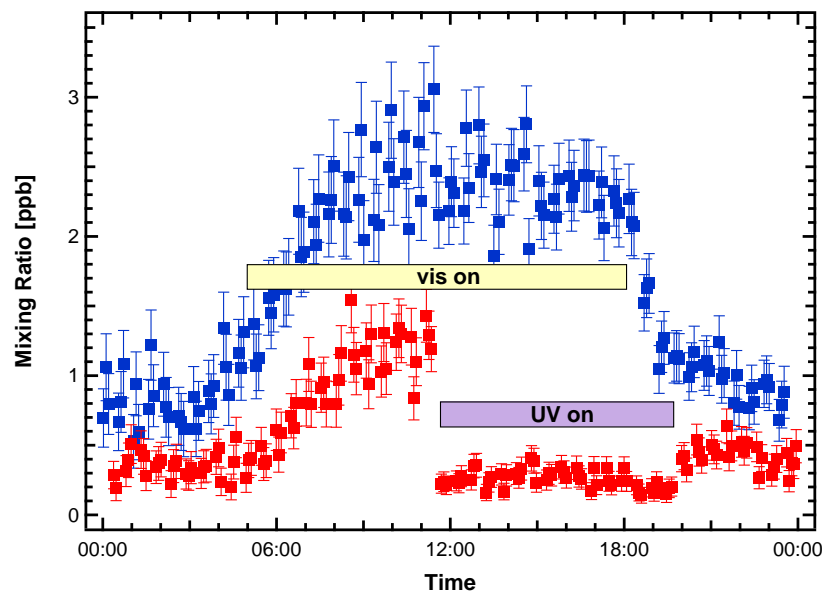

Fig. 2. Diurnal cycle of monoterpenes (MT) emitted from pine trees. The two traces show the total MT mixing ratios in the plant chamber (blue) and in the reaction chamber (red) as measured by PTR-MS. The MT mixing ratio rose in both chambers as soon as the visible light was switched on in the plant chamber (yellow horizontal bar) and reached a stable value around 09:00 h. The MT mixing ratio in the reaction chamber dropped close to zero as soon as UV light was switched on at 11:30 h (violet horizontal bar). At this point the particle formation event was initiated. Before $11: 45 \mathrm{~h}$ the MT in the reaction chamber were lower than in the plant chamber because of reactions with $\mathrm{O}_{3}$ and dilution by the supply flows stabilizing the $\mathrm{RH}$ and providing $\mathrm{O}_{3}$.

$\mathrm{O}_{3}$ and dilution. With the onset of UV illumination (11:45 h19:40 h, violet bar in Fig. 2), the MT concentrations in the reaction chamber dropped to $0.1-0.2 \mathrm{ppb}$ and remained low as long as the UV light was on. This additional drop was attributed to reactions of MT with $\mathrm{OH}$ produced by ozone photolysis.

A numerical model (based on FACSIMILE, AEA Technology) considering an ideal CSTR was developed to study the gas-phase processes in the reaction chamber. The measured mixing ratios of MT and SQT were smoothed and imposed as input parameters. The model considered dilution by the air flows containing ozone and water vapor and calculated concentrations of reactants and products in the reaction chamber, which were compared to PTR-MS measurements at the exit of the reaction chamber. As a first approximation we applied the rate coefficients $k_{\alpha-\text { pinene }+\mathrm{OH}}$ and $k_{\alpha-\text { pinene }+\mathrm{O}_{3}}$ and $k_{\beta}$-caryophyllene $+\mathrm{OH}$ and $k_{\beta}$-caryophyllene $+\mathrm{O}_{3}$ to model the oxidation of MT and SQT (Atkinson and Arey, 2003; Calogirou et al., 1999).

The $\mathrm{OH}$ steady state concentrations during UV illumination were calculated from the MT consumption and resulted in $(\mathrm{OH})=(3 \pm 2) \times 10^{7} \mathrm{~cm}^{-3}$. These $\mathrm{OH}$ steady state levels are consistent with the $\mathrm{OH}$ production rate, which was estimated from $\mathrm{O}_{3}$ consumption caused by UV photolysis assuming that the reaction of $\mathrm{O}^{1} \mathrm{D}$ with water vapour is the main additional loss process for $\mathrm{O}_{3}$ when the UV light is on. Detailed chemical interpretation will be subject of another paper.
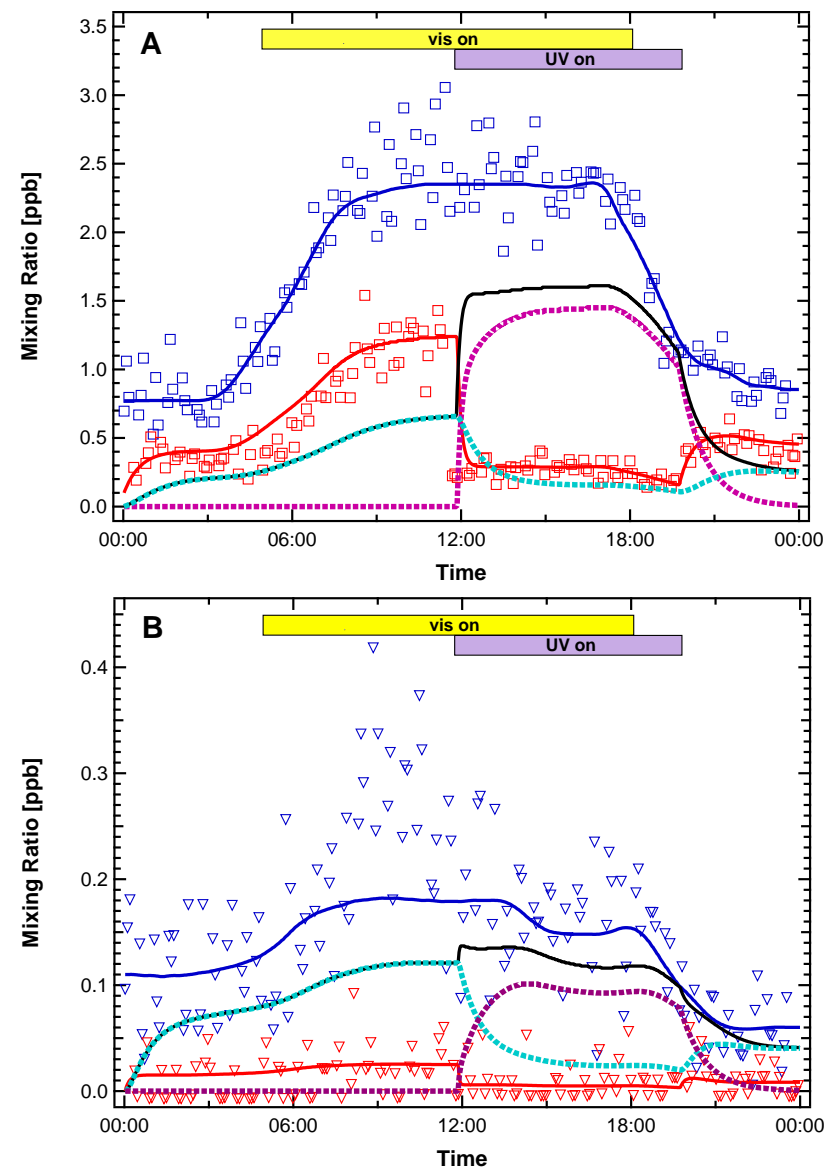

Fig. 3. The reaction chamber as continuous stirred tank reactor. Shown are the MT (A, squares) and SQT (B, triangles) emitted by pines as measured by PTR-MS in the plant chamber (blue) and in the reaction chamber (red). The observations were modeled by assuming the reactivity of $\alpha$-pinene with respect to $\mathrm{OH}$ and ozone as average reactivity for MT. As average reactivity for SQT the reactivity of $\beta$-caryophyllene with $\mathrm{OH}$ and $1 / 15$ of the reactivity of $\beta$-caryophyllene with ozone were applied. Model input (continuous blue lines) were the smoothed MT and SQT mixing ratios in the plant chamber. Model output (continuous red lines) were the MT and SQT mixing ratios in the reaction chamber. In this experiment $\mathrm{OH}$ concentration was estimated to $3 \times 10^{7} \mathrm{~cm}^{-1}$. The black lines describe the total throughput of MT and SQT, while the dotted turquoise and magenta lines give the contributions of $\mathrm{OH}$ and $\mathrm{O}_{3}$ reactions, respectively.

Figure 3 presents results from the model calculations for pine-emitted MT (Fig. 3A) and SQT (Fig. 3B). The experimental data and the model results show excellent agreement for the MT oxidation supporting the applicability of a CSTR model. Even small features such as the slight rise of the MT concentrations at the outlet of the reaction chamber when the UV light was turned off (19:40 h) were quantitatively captured by the model. 


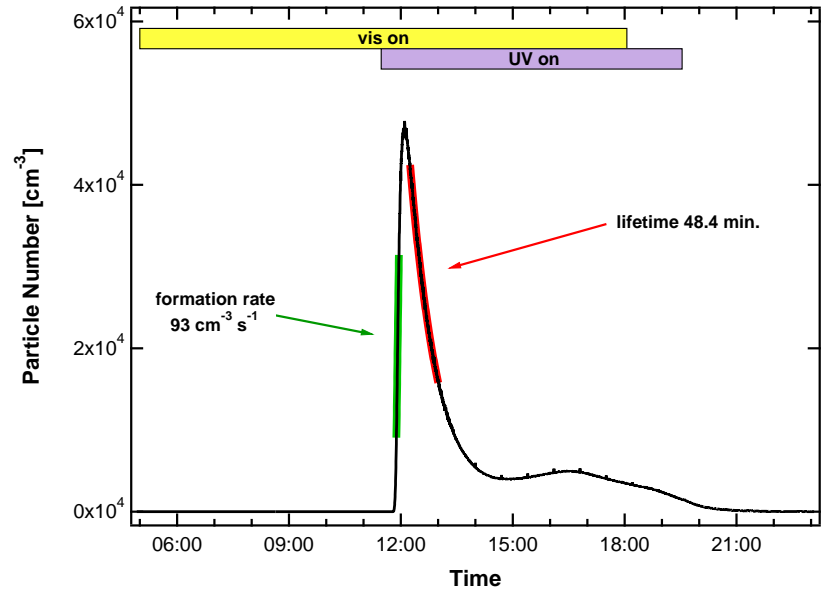

Fig. 4. Number density of particles as measured by the UCPC for pine reacted VOC. A few minutes after UV light was switched on (violet bar) in the reaction chamber a particle formation burst with a peak value of about 50000 particles was observed. The nearly linear rising edge was used to determine the particle formation rate $\mathrm{j}_{3 \mathrm{~nm}}$. The quasi exponential decay thereafter was used to estimate the lifetime of particles in the reaction chamber. Please note, that there was no new particle formation observed before the UV light was switched on. At 15:00 h a second weaker particle formation event occurred which lasted until UV light was switched off.

The reaction of MT with $\mathrm{OH}$ consumed the residual MT instantaneously, generated a pulse of oxidation products and initiated particle formation (shown in Fig. 4 and Fig. 5). The separation of the overall MT consumption (black line) into an $\mathrm{O}_{3}$ (magenta) and $\mathrm{OH}$ contribution (turquoise) shows that up to $90 \%$ of MT react with the $\mathrm{OH}$ radicals at the conditions in the reaction chamber (Fig. 3A).

Figure 3B shows the analogous plot with SQT data. Sesquiterpene emissions from pine were lower and thus more noisy than those of MT. SQT emissions increased after onset of twilight in a similar manner as the MT emissions and the SQT mixing ratios at the inlet of the reaction chamber reached a maximum of $400 \mathrm{ppt}$. No SQT were detectable at the outlet of the reaction chamber even when the UV light was off. This is attributed to the high reactivity of the SQT with ozone. In the first model calculations an average reactivity of the SQT towards $\mathrm{OH}$ and $\mathrm{O}_{3}$ such as $\beta$ caryophellene was applied (Atkinson and Arey, 2003; Calogirou et al., 1999), however, as shown in Fig. 3B, a 15fold reduced average rate coefficient of the SQT with $\mathrm{O}_{3}$ $\left(7.7 \times 10^{-16}\right.$ molec. $\left.\mathrm{cm}^{-3} \mathrm{~s}^{-1}\right)$ is sufficient to reproduce the experimental observations. Although virtually all SQT were consumed in the reactions with $\mathrm{O}_{3}$ no particle formation was observed without UV light. When the UV lamp was switched on, at $\mathrm{OH}$ concentrations of $\approx 3 \times 10^{7} \mathrm{~cm}^{-3}$, about $75 \%$ of the SQT reacted with $\mathrm{OH}$ (assuming a 15 times slower reactivity towards $\mathrm{O}_{3}$ than for $\beta$-caryophyllene). Neverthe-

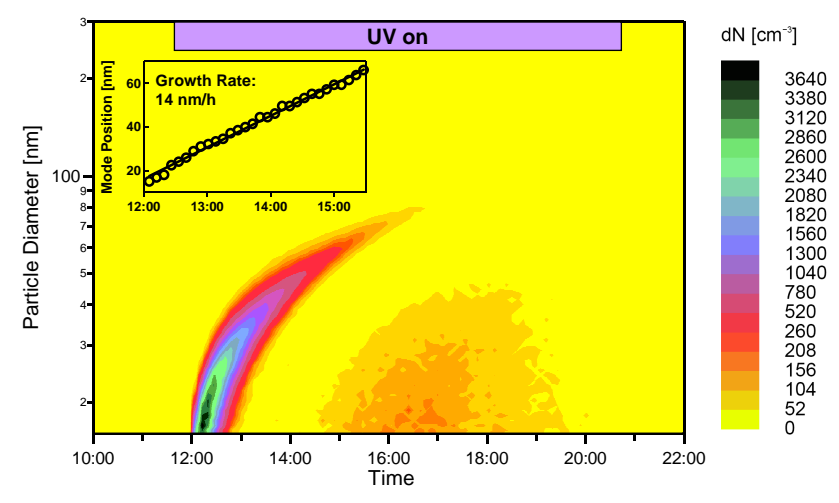

Fig. 5. Size distributions of particles formed by the oxidation of pine VOC's, shown as color plot. The colors give particle number concentration. When UV light was switched on (violet horizontal bar) a particle formation event took place. The particles were flushed out from the reaction chamber which was operated as CSTR. At 15:00 h a second particle formation event occurred. Here we focus on the first main event. From the mode position as function of time the growth rate was derived which was nearly constant over three hours (insert).

less, at the conditions in our chamber $\left(\left[\mathrm{O}_{3}\right] \approx 50 \mathrm{ppb}\right.$ and $[\mathrm{OH}] \approx 3 \times 10^{7} \mathrm{~cm}^{-3}$ ) the fraction of SQT reacting with $\mathrm{O}_{3}$ was still quite high $(\approx 25 \%)$ compared to that of MT $(<10 \%)$.

The initial VOC concentration in the reaction chamber was determined by GC-which were averaged for three hours before the particle formation event was initiated. The precursor concentrations as well as the speciation used for the analysis below are based on this $3 \mathrm{~h}$ average.

\subsubsection{Particulate phase observations}

At the conditions in the reaction chamber the products of MT and SQT ozonolysis did not induce new particle formation with detectable yields. However, the UV illumination initiated consumption of the residual VOC by OH (Fig. 2, 11:45 h) and particle formation (see Fig. 4 and Fig. 5). A maximum particle number $\mathrm{N}_{\max }$ of more than $4 \times 10^{4} \mathrm{~cm}^{-3}$ was reached about $15 \mathrm{~min}$ after the UV light was switched on (Fig. 4). Thereafter the particle number density decreased for two reasons. First, most of the VOC in the reaction chamber were oxidized by $\mathrm{OH}$ and the delivery of $\mathrm{VOC}$ from the plant chamber was not sufficient to keep the particle formation at a level as high as directly after $\mathrm{OH}$ production. Second, the increase of particle surface area provided a sufficient large condensational sink to suppress nucleation/activation.

The decrease of the particle number density with time followed an exponential curve with an e-fold lifetime of about 50 min which is somewhat shorter than the residence time of the air in the reaction chamber $(\approx 65 \mathrm{~min})$. The difference between residence time and decay time implied some contribution by coagulation and wall losses to the decay of 


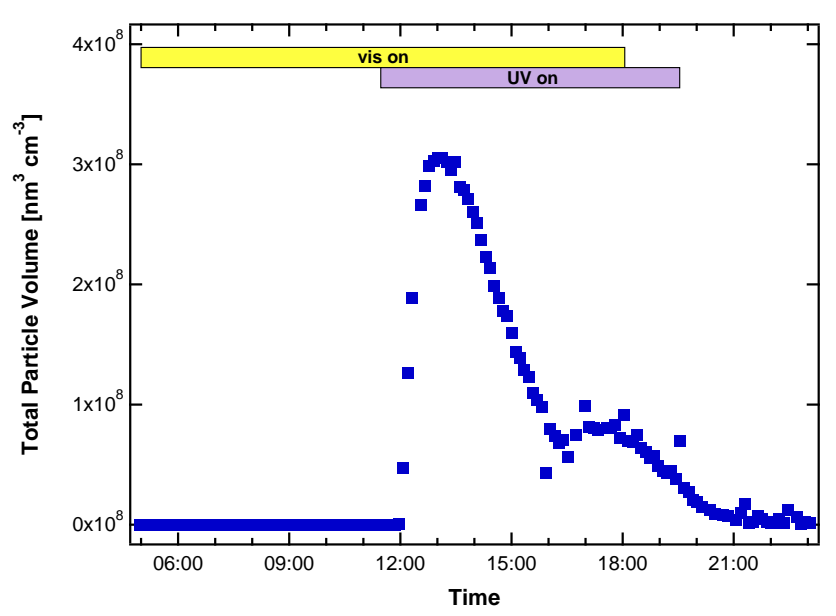

Fig. 6. Particle volume as a function of time. The total particle volume was calculated from the measured size distributions (Fig. 5). Periods of vis light in the plant chamber and UV light in the reaction chamber are indicated by yellow and violet bars. The maximum $V_{\max }$, here at 13:30 h, as distinguished point was used for the further analysis (see text).

particle number density. However, the dilution by flush out was the dominant loss process.

Approximate particle formation rates were deduced from the fast rising edge of the particle number density before reaching $\mathrm{N}_{\max }$, here $93 \mathrm{~cm}^{-3} \mathrm{~s}^{-1}$. Some hours later, a second weaker event occurred presumably because flush-out of aerosols reduced the condensational sink. An increase of the particle loss rate was observed when the UV lamp was switched off, indicating a small but persistent particle source in the reaction chamber after the second event.

The dynamics of the aerosol size distribution in our reaction chamber was characterized by particle formation, condensational growth, coagulation and flush-out. In particular the flush-out limited the count median diameter (CMD) to typically less than $100 \mathrm{~nm}$ (Fig. 5). Growth rates were derived from the increase of the CMD in time and were typically linear over several hours (here $14 \mathrm{~nm} \mathrm{~h}^{-1}$, see insert in Fig. 5). The total particle volume was calculated from integrated size distribution measurements. Figure 6 shows the total particle volume during the pine experiment. The maximum particle volume $\mathrm{V}_{\max }$ appeared typically about $90 \mathrm{~min}$ after the maximum in number density $\mathrm{N}_{\max }$. During this period, the particles grew fast enough to overcompensate the loss in particle number by flush out. A second, smaller particle formation event is recognizable by the small, relative maximum at 17:00 h. For the analysis below we chose the observed $\mathrm{V}_{\max }$ as distinguished reference points.

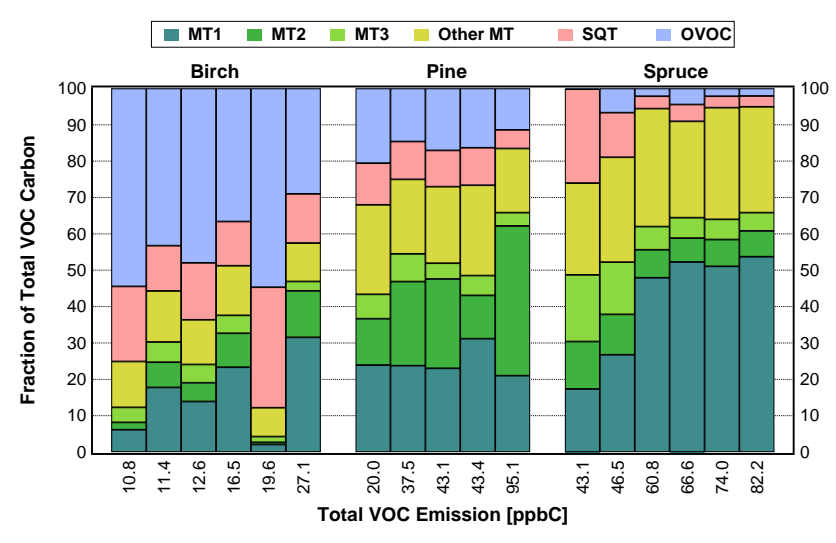

Fig. 7. Emission patterns of the boreal tree species classified in monoterpenes (MT, green), sesquiterpenes (SQT, pink), and oxygenated VOC (OVOC, blue). For monoterpenes the fractions of the three most abundant species of each tree MT1, MT2, and MT3 are indicated (compare Table 2). The absolute VOC mixing ratios in ppbC are shown on the category axis and are ordered with increasing VOC for each tree.

\subsubsection{Retrieval of SOA volume and SOA mass under CSTR conditions}

The particle formation events themselves lasted only for a few minutes, and the particle concentrations did not reach a steady state in the CSTR. This complicated the interpretation of the observed $V_{\max }$, because the same fraction of the number of particles in each size class is flushed out, but the volume is dominated by particles with large sizes. Number and volume of the particles which are flushed out in the course of an experiment were determined by applying a numerical, sectional aerosol dynamic model considering condensation, coagulation, and deposition within the CSTR. (This model is based on the work of Korhonen et al., 2003 and will be described elsewhere in detail.) The model calculations show that for each event at the time of observation of $V_{\max }$ the particle volume already flushed out of the reaction chamber is approximately the same as the observed particle volume $\mathrm{V}_{\max }$ itself. On average the flush out factor $F$ was $2.0 \pm 0.03$ and as a consequence we define the quantities $\mathrm{V}_{\operatorname{maxc}}$ which are the observed $\mathrm{V}_{\max }$ corrected by $F$. The particle loss during the period of a few minutes between the onset of the particle formation and the observed $\mathrm{N}_{\max }$ is negligible and affects the determined particle formation rates $\mathrm{j}_{3 \mathrm{~nm}}$ to less than $5 \%$.

The effective densities of the SOA are calculated by comparing the modal positions of the mass size distribution measured by the Q-AMS to those of the volume size distribution determined by the SMPS (DeCarlo et al., 2004; Saathoff et al., 2008). The SOA density was on average $1.25 \pm 0.15 \mathrm{~g} \mathrm{~cm}^{-3}$ and compares well with densities of monoterpene oxidation products determined by other groups (Bahreini et al., 2005; Kostenidou et al., 2007; $\mathrm{Ng}$ et al., 2006; Saathoff et al., 2008). For the experiment shown 
Table 2. Monoterpenes and sesquiterpenes on carbon basis.

\begin{tabular}{llll}
\hline VOC Class & Birch (\% of all VOC) & Pine (\% of all VOC) & Spruce (\% of all VOC) \\
\hline MT & $40 \%$ & $77 \%$ & $90 \%$ \\
SQT & $18 \%$ & $8 \%$ & $7 \%$ \\
OVOC* & $42 \%$ & $15 \%$ & $3 \%$ \\
Monoterpene** & Birch (\% of all MT) & Pine (\% of all MT) & Spruce (\% of all MT) \\
trans-ocimene & $45 \%$ & & \\
cis-ocimene & $17 \%$ & & \\
limonene & $9 \%$ & $37 \%$ & \\
$\Delta^{3}$-carene & & $32 \%$ & $9 \%$ \\
$\alpha-$ pinene & & & $9 \%$ \\
$\beta-$-pinene & & $7 \%$ & \\
camphene & & Pine (\% of all SQT) & Spruce (\% of all SQT) \\
Sesquiterpene*** & Birch (\% of all SQT) & $23 \%$ \\
$\alpha-$ farnesene & $15 \%$ & $19 \%$ & $39 \%$ \\
caryophyllene & $10 \%$ & $13 \%$ & \\
cadinene & & & \\
$\beta-$ cubebene & & & \\
longifolene & & & \\
\hline
\end{tabular}

* Due to stress impacts the plant emitted high amounts of OVOC such as (Z)-3-hexenol, $(Z)$-3-hexenylacetate, or methyl salicylate.

** The fractions of the monoterpenes labeled with MT1, MT2, MT3 in order of their abundance are also given in Fig. 7.

*** The class sesquiterpenes contained several compounds not positively identified but assigned to this class due to the typical peak at $m / z=204$. The contribution of these non attributed SQT to this class were $<7 \%$ for birch, $<15 \%$ for pine and $<5 \%$ for spruce.

in Fig. 6 the observed maximum total volume $\mathrm{V}_{\max }$ was $0.3 \times 10^{9} \mathrm{~nm}^{3} \mathrm{~cm}^{-3}$, which by applying $F$ and a density of $1.25 \mathrm{~g} \mathrm{~cm}^{-3}$ yields $0.75 \mu \mathrm{g} \mathrm{m}^{-3}$ organic mass at the maximum. The average density of $1.25 \mathrm{~g} \mathrm{~cm}^{-3}$ will be applied in the following. Detailed Q-AMS results will be discussed elsewhere.

\section{Results}

Figures 7 to 9 summarize 17 particle formation events observed for birch, pine, and spruce trees as emission sources as well as the 10 events done with $\alpha$-pinene from a diffusion source. The carbon mixing ratios at the abscissae in Figs. 8 and 9 were obtained as follows. The tree emissions observed during the 17 events were categorized into the three classes: monoterpenes (MT), sesquiterpenes (SQT) and oxygenated VOC (OVOC) as shown in Fig. 7. Isoprene concentrations were negligibly small. This categorization was chosen because MT and SQT comprise two well-defined isoprenoid classes and the class concentrations can be directly measured by the PTR-MS. Almost all MT and SQT react fast with $\mathrm{OH}$ radicals, often with rate coefficients close to the gaskinetic limit $\left(10^{-10} \mathrm{~cm}^{3}\right.$ molec. $\left.{ }^{-1} \mathrm{~s}^{-1}\right)$. However, rate coefficients for reactions of some SQT with $\mathrm{O}_{3}$ are quite high, while many MT react slower with $\mathrm{O}_{3}$. Therefore for SQT the ozonolysis constitutes a major pathway, whereas reaction with $\mathrm{OH}$ is the dominant pathway for MT in the atmosphere (and in our reaction chamber). The oxidation products of MT and SQT contribute to atmospheric SOA mass and presumably play an important role in new particle formation. In the reaction chamber, the bulk of MT and SQT were oxidized, in particular when the UV lamp was switched on. OH reactions alone consumed more than $90 \%$ of the MT (compare Fig. 3A). As the rate constants for $\mathrm{SQT}+\mathrm{O}_{3}$ reactions are quite high, an oxidative turnover of more than $98 \%$ is expected. This is confirmed by near-zero SQT concentrations which were observed in the reaction chamber even before the UV lamp was switched on (see Fig. 3B).

The OVOC category is composed of a diverse mixture small molecules such as methanol (Folkers et al., 2008; Hüve et al., 2007), LOX-products such as (Z)-3-hexenol (Heiden 
Table 3. Summary of observations and analysis.

\begin{tabular}{|c|c|c|c|c|}
\hline Quantity & Birch & Pine & Spruce & $\alpha$-Pinene \\
\hline \multicolumn{5}{|c|}{ SOA Volume: Consideration of MT+SQT } \\
\hline Volume Efficiency $\left[\mathrm{nm}^{3} \mathrm{~cm}^{-3} \mathrm{ppbC}^{-1}\right]$ & $47( \pm 5) \times 10^{+06}$ & $23( \pm 2) \times 10^{+06}$ & $18( \pm 3) \times 10^{+06}$ & $23( \pm 2) \times 10^{+06}$ \\
\hline Volume Formation threshold [ppbC] & $4 \pm 1$ & $5 \pm 4$ & $42 \pm 10$ & $67 \pm 11$ \\
\hline$R^{2}$ of the linear regression & 0.986 & 0.988 & 0.951 & 0.920 \\
\hline \multicolumn{5}{|c|}{ SOA Volume: Consideration of Various VOC Classes } \\
\hline Volume Efficiency MT only $\left[\mathrm{nm}^{3} \mathrm{~cm}^{-3} \mathrm{ppbC}^{-1}\right]$ & $44( \pm 13) \times 10^{+06}$ & $24( \pm 3) \times 10^{+06}$ & $15( \pm 3) \times 10^{+06}$ & $23( \pm 2) \times 10^{+06}$ \\
\hline$R^{2}$, linear regression MT only & 0.804 & 0.968 & 0.889 & 0.920 \\
\hline Volume Efficiency MT+SQT+OVOC $\left[\mathrm{nm}^{3} \mathrm{~cm}^{-3} \mathrm{ppbC}^{-1}\right]$ & $38( \pm 7) \times 10^{+06}$ & $21( \pm 2) \times 10^{+06}$ & $19( \pm 3) \times 10^{+06}$ & \\
\hline$R^{2}$, linear regression $\mathrm{MT}+\mathrm{SQT}+\mathrm{OVOC}$ & 0.910 & 0.981 & 0.910 & \\
\hline \multicolumn{5}{|c|}{ New Particle Formation } \\
\hline Formation Rates $j_{3 \mathrm{~nm}}\left[\mathrm{~s}^{-1} \mathrm{~cm}^{-3}\right]$ & $6-89$ & $18-182$ & $1-44$ & $20-130$ \\
\hline Average Formation Rate $\left[\mathrm{s}^{-1} \mathrm{~cm}^{-3}\right]$ & $23 \pm 31$ & $103 \pm 58$ & $19 \pm 17$ & $44 \pm 35$ \\
\hline Number Efficiency [ $\mathrm{s}^{-1} \mathrm{~cm}^{-3} \mathrm{ppbC}^{-1}$ ] & $6.1 \pm 0.4$ & $4.7 \pm 0.4$ & $1.0 \pm 0.2$ & $1.4 \pm 0.3$ \\
\hline Number Formation Threshold [ppbC] & $5 \pm 1$ & $12 \pm 3$ & $43 \pm 13$ & $72 \pm 20$ \\
\hline$R^{2}$, linear regression $\left(\mathrm{j}_{3 \mathrm{~nm}}<140 !\right)$ & 0.984 & 0.985 & 0.850 & 0.760 \\
\hline \multicolumn{5}{|c|}{ Particle Growth } \\
\hline Growth Efficiency $\left[\mathrm{nm} \mathrm{h}^{-1} \mathrm{ppbC}^{-1}\right]$ & $0.39 \pm 0.13$ & $0.10 \pm 0.03$ & $0.14 \pm 0.06$ & $0.13 \pm 0.01$ \\
\hline Intercept Growth $\left[\mathrm{nm} \mathrm{h}^{-1}\right]$ & $11 \pm 2$ & $12 \pm 2$ & $6 \pm 4$ & $8 \pm 2$ \\
\hline$R^{2}$, linear regression & 0.760 & 0.798 & 0.556 & 0.951 \\
\hline \multicolumn{5}{|c|}{ Fractional Mass Yields Consideration of MT only and MT+SQT } \\
\hline Fractional Mass Yield MT+SQT & $0.11 \pm 0.01$ & $0.053 \pm 0.005$ & $0.042 \pm 0.007$ & \\
\hline Fractional Mass Yield MT only & $0.10 \pm 0.03$ & $0.053 \pm 0.006$ & $0.035 \pm 0.006$ & $0.052 \pm 0.005$ \\
\hline
\end{tabular}

et al., 2003) or some long chain aldehydes such as nonanal (Wildt et al., 2003). Most of the OVOC react slower with ozone than the MT, so reaction with $\mathrm{OH}$ radicals is probably their major loss pathway. The role of oxygenated compounds as precursors for particle formation and growth is not quite clear. In the reaction chamber the concentrations of some OVOC were drastically reduced due to oxidation by $\mathrm{OH}$. Only for a few OVOC such as methanol and acetone, a strong increase was observed when the UV lamp was switched on, presumably due to oxidative degradation of other VOC.

For each class the VOC concentrations were weighted with the number of carbon atoms of the respective VOC leading to carbon mixing ratios in $\mathrm{ppbC}$. These were calculated from the average of $3 \mathrm{~h}$ of GC-MS measurements before new particle formation was initialized. The relative contributions of MT, SQT and OVOC to the total amount of carbon averaged over all events for each tree are given in Table 2. Birch had the largest fraction of OVOC and SQT. Pine had a substantial fraction of OVOC and spruce emissions were composed mainly of MT and SQT. Figure 7 summarizes the emission patterns for all events in terms of these classes as relative concentrations. The absolute, total concentrations of VOC in ppbC are given for each event at the category axis in Fig. 7. As we will show in the following, quantities characterizing particle formation events such as SOA volume, particle formation and growth rates are related to these carbon mixing ratios in a relatively simple fashion. Table 2 specifies the most abundant MT and SQT observed in the experiments with the trees. For pine $\alpha$-pinene and $\Delta 3$-carene are the main MT components together with some camphene. The main MT component of the spruce was limonene, together with similar contributions of $\alpha$-pinene and $\beta$-pinene as secondary 
components. The birch emitted cis- and trans-ocimene, and limonene. Together with the relative high SQT and OVOC emissions, this indicates that the birch faced some stress. Also the first day of spruce showed enhanced SQT fraction, indicating delay in adaptation. We nevertheless included all these moderate cases to enhance the coverage of possible scenarios.

In all cases, both UV-light and $\mathrm{OH}$ radicals were essential in inducing new particle formation at our experimental conditions and within our dynamic range of emissions concentrations of up to $10 \mathrm{ppbC}$. Herein, the $\mathrm{OH}$ reached steady state concentrations of about $3 \times 10^{7} \mathrm{~cm}^{-3}$, as described above. Ozonolysis alone did not induce new particle formation with detectable yields, although all SQT and a portion of the MT were consumed by ozone (including a contribution by dark $\mathrm{OH}$ arising from the ozonolysis of unsaturated VOC, since we did not use $\mathrm{OH}$-scavengers, see Atkinson and Aschmann, 1993; Paulson et al., 1992, 1998).

In Fig. 8 we relate the total volume of $\mathrm{SOA}\left(\mathrm{V}_{\operatorname{maxc}}\right)$ for tree emissions and for $\alpha$-pinene to carbon mixing ratios of VOC. The $\mathrm{V}_{\operatorname{maxc}}$ are the observed $\mathrm{V}_{\max }$ corrected by $F=2.0$ for particle flush-out as discussed in Sect. 2.3.2. The carbon mixing ratios given on the $\mathrm{x}$-axis in Fig. 8 are the $3 \mathrm{~h}$ average of the mixing ratios in the plant chamber corrected for dilution, thus the hypothetical steady state levels of the respective precursors in the reaction chamber if there were no reactions. Figure 8 compares the importance of the emission classes in terms of MT and the sums of MT+SQT and $\mathrm{MT}+\mathrm{SQT}+\mathrm{OVOC}$. The data points in Fig. 8 consider the carbon mixing ratio of the sum of MT+SQT.

We found simple linear relationships between the mixing ratios of $\mathrm{MT}+\mathrm{SQT}$ and $\mathrm{V}_{\operatorname{maxc}}$ for all tree species studied and $\alpha$-pinene. The linear regression curves have positive $\mathrm{x}$-intercepts. Slope, $\mathrm{x}$-intercept, and correlation coefficient $\left(R^{2}\right)$ of the linear regressions are shown in Table 3. A linear regression was also performed by taking into account the MT portion only and by considering the total carbon comprising MT+SQT+OVOC. For comparison we added the resulting best fit lines of these two cases in Fig. 8. The slope, X-intercepts and $R^{2}$ of these fits are also listed in Table 3. For each tree species the values of $R^{2}$, i.e. the quality of the fit did not depend much on the choice of the VOC basis.

The comparison of the best fit lines for the different approaches in Fig. 8 shows that neglecting the sesquiterpenes in the sum of MT+SQT for pine and spruce does not have much effect on the slopes and on the X-intercepts. This is due to the relatively small contributions of SQT to the emissions. Only the first data point for spruce comprises a relative large fraction of SQT. In case of the birch where SQT on average contributed about $14 \%$ to the emissions, omission of the SQT leads to a change of $7 \%$ in the slope and a decrease of the $\mathrm{X}$-intercept by $4 \mathrm{ppbC}$ to zero. The inclusion of OVOC to MT+SQT has an effect in case of the birch because the OVOC concentrations were high; the influence is weaker for pine and negligible for spruce. Because of the uncertainty

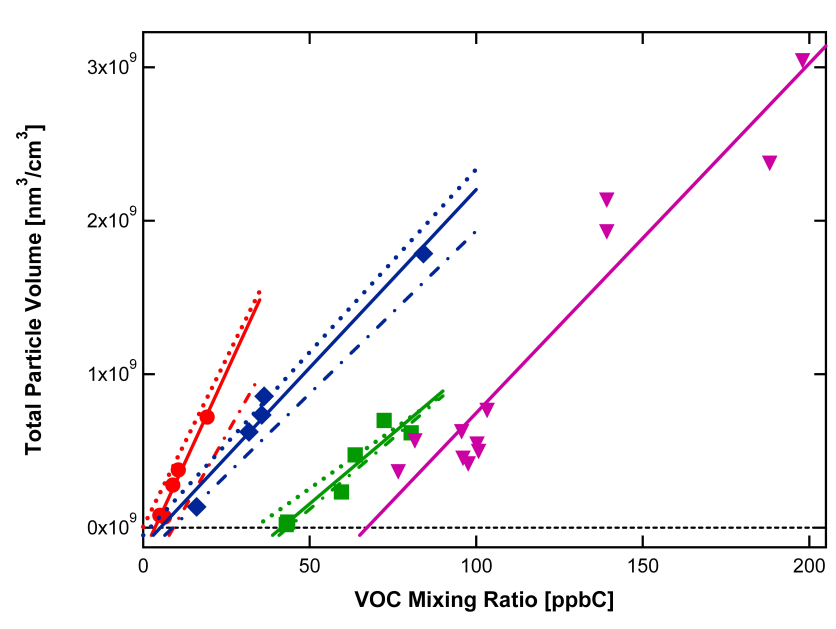

Fig. 8. Linear relations between maximum particle volume $\mathrm{V}_{\operatorname{maxc}}$ and the carbon mixing ratio in the reaction chamber for emissions of birch (red circles), pine (blue diamonds), spruce (green squares), and $\alpha$-pinene (magenta triangles). $\mathrm{V}_{\operatorname{maxc}}$ was corrected by $F=2$ for flush out of particles from the reaction chamber operated as CSTR. The symbols consider carbon mixing ratios based on MT+SQT, solid lines are linear fits to the symbols. The dotted and dashed dotted lines are linear regression lines based on carbon mixing ratios of MT only and on all three classes MT+SQT+OVOC, respectively. (details see text). The intercepts with the $\mathrm{ppbC}$ axis indicate volume formation thresholds, i.e. the amount of carbon which must be consumed before particle volume can be formed.

about the fraction of OVOC that serve as potential SOA precursor, we will focus analysis and discussion on the sum of $\mathrm{MT}+\mathrm{SQT}$.

The linear relations between MT+SQT carbon mixing ratios and $\mathrm{V}_{\operatorname{maxc}}$ for the trees and $\alpha$-pinene have differences in the slopes and significant differences in the intercepts. The slopes of the linear regressions shown in Fig. 8 give a volume efficiency of SOA formation for each tree species and for $\alpha$ pinene in terms of generated SOA volume per ppbC emission concentration in the reactor. The volume efficiency obtained for the emissions of pine and spruce was the same as that for $\alpha$-pinene within the errors. The average of these three cases amounts to $21 \pm 3 \times 10^{6} \mathrm{~nm}^{3} \mathrm{~cm}^{-3} \mathrm{ppbC}^{-1}$. For birch the SOA efficiency $\left(47 \pm 5 \times 10^{6} \mathrm{~nm}^{3} \mathrm{~cm}^{-3} \mathrm{ppbC}^{-1}\right)$ is about a factor of two larger (Table 3 ). Note that a volume concentration of $1 \times 10^{6} \mathrm{~nm}^{3} \mathrm{~cm}^{-3}$ corresponds to a mass concentration of $1 \mathrm{ng} \mathrm{m}^{-3}$, if the unit density of $1 \mathrm{~g} \mathrm{~cm}^{-3}$ is applied. We calculated the $\mathrm{x}$-intercepts at the ppbC-axis (see Fig. 8 and Table 3), since these characterize a threshold for the onset of new particle formation at the $\mathrm{OH}$ levels of a few times $10^{7} \mathrm{~cm}^{-3}$ in the reaction chamber. Independent of the OVOC being included or not, all tree emissions had distinctively lower ppbC-intercept, i.e. indicating potentially lower particle formation thresholds than $\alpha$-pinene.

We observed particle number formation rates $\mathrm{j}_{3 \mathrm{~nm}}$ between 1 and $182 \mathrm{~cm}^{-3} \mathrm{~s}^{-1}$ for the tree emissions: Six events 


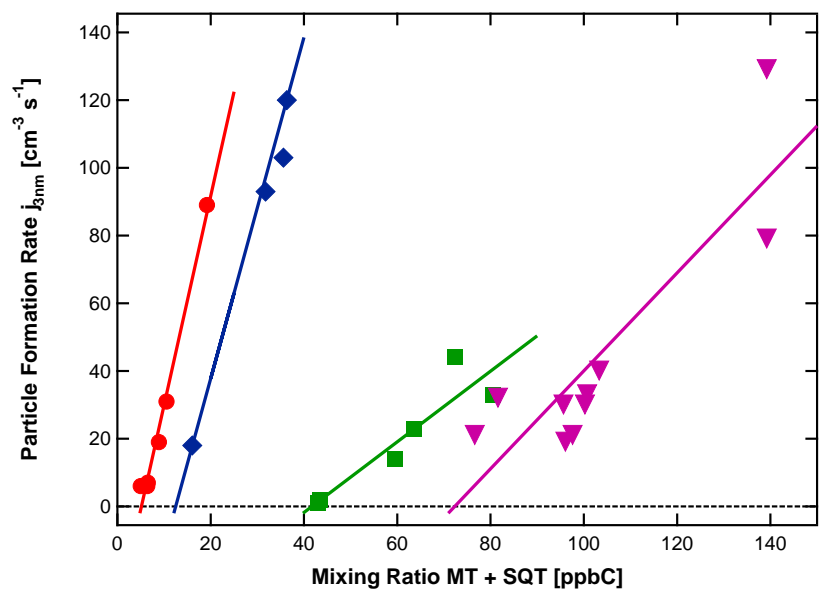

Fig. 9. Particle formation rates $j_{3 \mathrm{~nm}}$ as a function of the carbon mixing ratio of MT+SQT for emissions of birch (red circles), pine (blue diamonds), spruce(green squares), $\alpha$-pinene (magenta triangles). Only nucleation rates smaller than $140 \mathrm{~cm}^{-3} \mathrm{~s}^{-1}$ were considered. The slope of the linear regression lines give particle formation efficiency in terms of particles formed per volume and time per ppbC consumed. Intercepts with the ppbC axis indicate particle formation thresholds, i.e. the amount of carbon which must be consumed before new particles can be detected.

with $\mathrm{j}_{3 \mathrm{~nm}} \leq 10 \mathrm{~cm}^{-3} \mathrm{~s}^{-1}$ were observed, 7 events with 10 $<\mathrm{j}_{3 \mathrm{~nm}} \leq 50 \mathrm{~cm}^{-3} \mathrm{~s}^{-1}, 5$ events with $\mathrm{j}_{3 \mathrm{~nm}} \geq 90 \mathrm{~cm}^{-3} \mathrm{~s}^{-1}$. The average particle formation rate was $44 \mathrm{~cm}^{-3} \mathrm{~s}^{-1}$. In the $\alpha$ pinene reference experiments $\mathrm{j}_{3 \mathrm{~nm}}$ was in the range of 20 to $130 \mathrm{~cm}^{-3} \mathrm{~s}^{-1}$, with the majority ( 8 out of 10 ) between 20 and $40 \mathrm{~cm}^{-3} \mathrm{~s}^{-1}$. If we omit the largest particle formation rate of $182 \mathrm{~cm}^{-3} \mathrm{~s}^{-1}$ for pine, the formation rates $<140 \mathrm{~cm}^{-3} \mathrm{~s}^{-1}$ observed for the trees scale approximately linearly with the concentration of MT+SQT in ppbC as defined above (Fig. 9). This trend was also recognizable with $\alpha$-pinene although the data were more scattered (see $R^{2}$, Table 3 ). The slopes of the linear fits to $j_{3 n m}=f(p p b C)$ define a number efficiency of the formation of new particles in terms of particles formed per $\mathrm{cm}^{3}$ and $\mathrm{s}$ per ppbC for each tree and for $\alpha$-pinene. Birch $\left(6 \mathrm{~cm}^{-3} \mathrm{~s}^{-1} \mathrm{ppbC}^{-1}\right)$ and pine $\left(5 \mathrm{~cm}^{-3} \mathrm{~s}^{-1} \mathrm{ppbC}^{-1}\right)$, were more efficient in forming new particles than spruce and $\alpha$ pinene (both about $1 \mathrm{~cm}^{-3} \mathrm{~s}^{-1} \mathrm{ppbC}^{-1}$ ). As can be seen in Fig. 9 the linear regression lines intercept the ppbC-axis at about the same positive values within the errors as in the case of $\mathrm{V}_{\text {maxc }}$ in Fig. 8. This confirms our interpretation of the positive intercepts at the ppbC-axis as particle formation thresholds. We will discuss these thresholds later.

Growth was linear for each event over $2-3 \mathrm{~h}$ as indicated in the insert in Fig. 5. Thus we attribute specific growth rates GR to each particle event. The GR for the tree emissions were in the range $10-20 \mathrm{~nm} \mathrm{~h}^{-1}$ with an average of $14 \pm 3 \mathrm{~nm} \mathrm{~h}^{-1}$ for all events. In the dynamic range of emission concentrations investigated here, the GR depend linearly on the carbon mixing ratio of $\mathrm{MT}+\mathrm{SQT}$, like $\mathrm{V}_{\operatorname{maxc}}$ and $\mathrm{j}_{3 \mathrm{~nm}}$. The slopes of the linear regressions of the GR as a function of the carbon mixing ratio define growth efficiencies (growth rate per ppbC). For the two conifers the growth efficiencies are $0.10 \pm 0.03$ and $0.14 \pm 0.01 \mathrm{~nm} \mathrm{~h}^{-1} \mathrm{ppbC}^{-1}$, respectively, which is the same as that for $\alpha$-pinene of $0.13 \pm 0.01 \mathrm{~nm} \mathrm{~h}^{-1} \mathrm{ppbC}^{-1}$ within the uncertainties of the experimental results. For birch, a larger growth efficiency of $0.38 \pm 0.13 \mathrm{~nm} \mathrm{~h}^{-1} \mathrm{ppbC}^{-1}$ was observed (Table 3 ). The $\mathrm{y}$ intercepts are non-zero, in a range of $5-10 \mathrm{~nm} \mathrm{~h}^{-1}$ but the same for all within the error limits.

\section{Discussion}

\subsection{Performance of the setup}

The setup with separated plant and reaction chambers demonstrates the ability to independently control the physiological state of the plants (by managing their environment $-\mathrm{T}, \mathrm{RH}, \mathrm{CO}_{2}, \mathrm{PPFD}$ ) while keeping the conditions in the reaction chamber constant. The size of the plant chamber allows whole individual plants or groups of plants to be used instead of branches or single leaves. By simulating a diurnal PPFD cycle and by applying different temperatures in the plant chamber, the VOC emissions from the plants and thus the input into the reaction chamber was varied over more than an order of magnitude without exposing the plants to extreme unnatural conditions. In the reaction chamber the conditions were constant during particle formation events that lasted for several hours. In the natural environment neither temperature nor the intensity of visible light and UV light are constant over such a long time. However, the constant conditions enable comparison between the results obtained for different plants and for $\alpha$-pinene. Our setup thus allows controlled experiments of particle formation, nevertheless reflecting the complexity and the highly mixed states of plant emitted VOC.

The emission patterns of boreal trees in the plant chambers reflect conditions observed in the boreal forest. Tarvainen et al. (2007) identified $\alpha$-pinene, $\beta$-pinene, $\Delta^{3}$-carene, and limonene as the major components in the south and middle boreal forest from spring to autumn. The same compounds were also the major MT components emitted by the plants in our chamber (see Table 2). In addition, ocimenes are a major late spring and summer emissions of birch, and a major component of the MT emissions in the boreal forest during summer and autumn. The average SQT/MT ratio of $10 \%$ for all the experiments with spruce and pine match the SQT/MT ratio in the boreal forest during the growing season (Tarvainen et al., 2007). The average mass SQT/MT ratio measured here was higher (46\%) only for experiments with birch. However, such large SQT/MT ratios were reported for the late summer in the boreal forest (Tarvainen et al., 2007). We suggest that the enhanced SQT/MT originate from plant stress. This is supported by the high OVOC levels observed here, too. 
Possibly the birch trees in our experiments faced a similar form of (unknown) stress as birch trees in the late summer. Considering the natural plant-to-plant variability our experiments simulate emission pattern in the Finnish boreal forest quite well and provided thus a realistic source of precursors for SOA formation in boreal forests.

The VOC concentrations during the plant chamber experiments were well below $10 \mathrm{ppb}$ in most cases $(<100 \mathrm{ppbC}$, see Fig. 7), which is on the low side compared to most other laboratory and chamber studies. The MT concentrations are still somewhat high compared to the sub-ppb levels of MT at the canopy level in the boreal forest (Haapanala et al., 2007; Hakola et al., 2003). It is noted though that the majority of data points obtained in our experiments (12 out of 17) were at MT levels below $4 \mathrm{ppb}$.

The $\mathrm{O}_{3}$ levels in the dark reaction chamber were $\approx 80 \mathrm{ppb}$, about 2 times higher than those typically observed in Hyytiälä in spring and early summer during particle formation events (Lyubovtseva et al., 2005). However, when UV light was turned on, the ozone level dropped to $30-40 \mathrm{ppb}$, comparable to those in Hyytiälä at day time. An obvious difference between the environment and our reaction chamber were the $\mathrm{OH}$ concentrations, which are estimated to be $1-5 \times 10^{7} \mathrm{~cm}^{-3}$, roughly an order of magnitude higher than values of $5 \times 10^{5}-5 \times 10^{6} \mathrm{~cm}^{-3}$ observed in spring and summer in Hyytiälä (Boy et al., 2005; Lyubovtseva et al., 2005).

Other properties that are necessary in order to classify the conditions during SOA formation are $\mathrm{NO}_{\mathrm{x}}$ concentrations and $\mathrm{RH}$. The only $\mathrm{NO}_{\mathrm{x}}$ source in our current setup is direct NO emission from the plants (Wildt et al., 1997; Hari et al., 2003). The NO concentrations at the exit of the plant chamber were always below $300 \mathrm{ppt}$, therefore maximum $\mathrm{NO}_{\mathrm{x}}$ concentrations in the reaction chamber were always well below 300 ppt. The RH in the reaction chamber was regulated to $\sim 65 \%$, with one exception of $\sim 50 \%$ for the spruce experiments. According to the classification of laboratory studies of SOA formation, our experiments were carried out in the low $\mathrm{NO}_{X}, \mathrm{UV}$, and high $\mathrm{RH}$ regime (Pathak et al., 2007a).

The abscissae in Figs. 8 and 9 show the stabilized VOC concentration in the plant chamber. During a nucleation event, the steady state concentration of MT and SQT drops to near zero, as they are almost quantitatively consumed by $\mathrm{OH}$ radicals and ozone (Fig. 3A, Fig. 3B). Thus, the initial hypothetical steady state concentration of MT+SQT in the reaction chamber is also a direct measure of the overall MT+SQT consumption. The hypothetical steady state concentration cannot be observed in the reaction chamber because almost all SQT and about half of the MT are already consumed by ozonolysis before the UV light in the reaction chamber is turned on (compare Fig. 3A, Fig. 3 B). As a consequence, a substantial portion of the carbon of the plantemitted VOC is already converted into ozonolysis products, before the nucleation events were initiated. Nevertheless, $\mathrm{V}_{\text {maxc }}$, and $\mathrm{j}_{3 \mathrm{~nm}}$ scale linearly with this hypothetical steady state VOC concentration. We explain this by (i) that the oxi- dation by ozone still conserves the carbon mixing ratio in the reaction chamber. This is inherent to a CSTR in steady state, if there are no other substantial losses than the flush out. (ii) The ozonolysis products are oxidized by $\mathrm{OH}$ when UV light is on and their carbon contributes to $\mathrm{V}_{\max }$ and $\mathrm{j}_{3 \mathrm{~nm}}$. GCMS measurements in the reaction chamber during an event confirmed that the first generation products (such as pinonaldehyde and nopinone) were indeed absent, and were likely consumed by $\mathrm{OH}$ radicals.

Under the limitations discussed above, the experiments were conducted as near as possible to those in the natural environment. As argued in Rudich et al. (2007), enhanced VOC concentrations and oxidant levels can cause difficulties in the transferability of chamber results to atmospheric conditions. The influence of the somewhat high $\mathrm{VOC}$ and $\mathrm{OH}$ concentrations on particle formation in our system is estimated based on the experiments with the $\alpha$-pinene diffusion source instead of plants. An incremental mass yield of 5.2\% can be derived from the slope for $\alpha$-pinene in Fig. 8, applying particle density of $1.25 \mathrm{~g} \mathrm{~cm}^{-3}$. Although there are not many low concentration data in the literature to which our results can be compared, SOA mass fractions of 5\% are found at SOA mass loads around $2 \mu \mathrm{g} \mathrm{m}^{-3}$ in $\alpha$-pinene experiments summarized by Pathak et al. (2007a, b). The x-intercept indicates an onset of particle formation at $7 \mathrm{ppb}$ (details see below). These findings agree best with results at the low $\mathrm{NO}_{\mathrm{x}}$, UV, low RH regime compiled by Pathak et al. (2007a).

The mixing ratios of the VOC under investigation were low ( $<10 \mathrm{ppb}$ on molecule basis) and the observed particle volumes $\mathrm{V}_{\max }$ were less than $0.8 \times 10^{9} \mathrm{~nm}^{3} \mathrm{~cm}^{-3}$ for the trees and in most $\alpha$-pinene experiments. (Recall, that $\mathrm{V}_{\operatorname{maxc}}$ in Fig. 8 are a factor of 2 larger than the actual observed $\mathrm{V}_{\max }$ because of the correction for flush out.) This corresponds to actual mass loadings in the sub $\mu \mathrm{g} \mathrm{m}^{-3}$ range. SOA mass concentrations of a few tenth of a $\mu \mathrm{g} \mathrm{m}^{-3}$ are compatible with the organic mode in the range $\mathrm{D}_{v a}=50$ $100 \mathrm{~nm}$ observed in Hyytiälä by Allan et al. (2006) $10-18 \mathrm{~h}$ after a nucleation event. Allan et al. (2006) attributed this to the organic fraction in newly formed particles. Such low mass loadings together with the linearity between consumed ppbC and observed $V_{\operatorname{maxc}}$ (Fig. 8) indicate that our measurements were not strongly influenced by absorptive uptake of volatile- and semi-volatile compounds. According to considerations of Donahue et al. (2006), for a particle mass load of $1 \mu \mathrm{g} \mathrm{m}^{-3}$ the vapor pressure of compounds which partition to equal fractions in gas phase and particulate phase is also about $1 \mu \mathrm{g} \mathrm{m}^{-3}$. For comparison: for pinonaldehyde $1 \mu \mathrm{g} \mathrm{m}^{-3}$ corresponds to a mixing ratio of $150 \mathrm{ppt}$ or a saturated aqueous solution of glutaric acid has a vapor pressure of about $1 \mathrm{ppb} \approx 5 \mu \mathrm{g} \mathrm{m}^{-3}$ (Bilde et al., 2003; Koponen et al., 2007). As a consequence, we believe that the enhanced $\mathrm{OH}$ concentrations and the somewhat elevated VOC concentrations merely compressed the temporal evolution of the entire photo-chemical system and the time evolution of new particle formation. 
We thus conclude that our reaction system realistically simulates many aspects of natural VOC oxidation and particle formation and that our results may thus be reliably scaled down to lower VOC concentrations. This is corroborated by the fact that both, our average GR and average particle formation rate are scaling in similar fashion to those observed in Hyytiälä. Our lowest GR of about $10 \mathrm{~nm} \mathrm{~h}^{-1}$ (average $14 \mathrm{~nm} \mathrm{~h}^{-1}$ ) is 3-4 times larger than the average growth rate observed in Hyytiälä $\left(3 \mathrm{~nm} \mathrm{~h}^{-1}\right.$, Kulmala et al., 2001). At the same time our lowest observed particle formation rates $\mathrm{j}_{3 \mathrm{~nm}}$ are in the range $1-20 \mathrm{~cm}^{-3} \mathrm{~s}^{-1}$ which is up to an order of magnitude larger than particle formation rates in Hyytiälä $\left(1-2 \mathrm{~cm}^{-3} \mathrm{~s}^{-1}\right.$, Kulmala et al., 2007).

\subsection{The role of ozonolysis vs. $\mathrm{OH}$ oxidation in new par- ticles formation}

New particle formation was not observed before $\mathrm{OH}$-radicals were generated, suggesting a minor direct role of MT and SQT ozonolysis in new particle formation. In contrast to MT, the SQT were quantitatively consumed by ozonolysis. Therefore, we may conclude that, even at the somewhat enhanced VOC concentrations in our reaction chamber, 50$65 \% \mathrm{RH}$, and $80 \mathrm{ppb}$ of $\mathrm{O}_{3}$, ozonolysis products of sesquiterpenes do not initiate formation of new particles. We also find that under these conditions, MT ozonolysis products do not induce particle formation. This is in contrast to observations in static chambers and in contrast to the laboratory study with $\beta$-caryophyllene (Bonn and Moortgat, 2003). Bonn and Moortgat (2003) concluded that the reaction of the sesquiterpenes with ozone should most likely be the origin of the observed atmospheric biogenic secondary organic aerosol (SOA) formation.

Indeed, new particle formation occurs only during day time in the boreal forest, in accordance with our observations (Kulmala et al., 2004b). Lyubovtseva et al. (2005) find a correlation between high $\mathrm{O}_{3}$ levels and new particle formation in springtime and wintertime, but this seems to be more related to $\mathrm{O}_{3}$ dependent $\mathrm{OH}$ production than to direct ozonolysis reactions. However, it is possible that oxidation products of the ozonolysis of SQT or MT, once they react further with $\mathrm{OH}$ radicals, play a pivotal role in new particle formation and contribute to condensational growth and SOA mass. We observe the consumption of ozonolysis products as soon as the UV-light is switched on and $\mathrm{OH}$ radicals are generated. These findings are consistent with observations multistep oxidation in SOA formation ( $\mathrm{Ng}$ et al., 2006), with the suggestion of oxygenated precursors as a persistent source of organic aerosols in the free troposphere (Heald et al., 2005), and in the boreal forests (Laaksonen et al., 2008).

\subsection{SOA formation potentials of tree emissions}

One goal of these experiments is to attribute SOA formation potentials to species and tree stands (i.e. several trees emit- ting). A key to that are the simple linear relationships between the observed particle volume $\mathrm{V}_{\operatorname{maxc}}$ or the new particle formation rate $\mathrm{j}_{3 \mathrm{~nm}}$ and the carbon mixing ratio of the tree emissions (Fig. 8 and Fig. 9). The slopes of these linear regression lines enable to attribute SOA formation potentials to each tree species with respect to production of new particles, which we term the number efficiency, and to estimate production of SOA volume, which we term volume efficiency.

Positive intercepts on the ppbC axis for both, $\mathrm{V}_{\operatorname{maxc}}$ and $j_{3 \text { nm }}$ (Fig. 8 and Fig. 9, Table 3) were found. These give the minimum amount of VOC that must be oxidized under the given conditions to generate sufficient low vapor pressure products and thus new particles, in other words thresholds for new particle formation. Remarkably, we obtain the same ppbC intercepts in both, $\mathrm{j}_{3 \mathrm{~nm}}$ and $\mathrm{V}_{\operatorname{maxc}}$ for each tree and $\alpha$-pinene within the statistical errors. The thresholds for number and volume formation in systems without preexisting seed particles should indeed be the same, because volume can only be formed by condensation after seeds had nucleated. Thus, this agreement points out the consistency of our observations. If we average the results from $\mathrm{V}_{\operatorname{maxc}}$ and $\mathrm{j}_{3 \mathrm{~nm}}$ to a single particle formation threshold, we end up with $5 \pm 1,9 \pm 6,43 \pm 16,70 \pm 22 \mathrm{ppbC}$ for birch, pine, spruce and $\alpha$-pinene, respectively. It should be noted that the spruce experiments were performed at somewhat lower $\mathrm{RH}$, than all others, $50 \%$ compared to $65 \%$, and that there are indications that $\mathrm{j}_{3 \mathrm{~nm}}$ depends on humidity. This is currently under closer investigation, and therefore all comparisons of spruce with the other systems require some care. Taken together, these data indicate that the particle formation thresholds of birch and pine at $65 \% \mathrm{RH}$ are identical within the errors, but lower than that of spruce at $50 \% \mathrm{RH}$ and $\alpha$-pinene.

Considering number efficiencies (slopes in Fig. 9, Table 3), again birch and pine are most effective, while spruce (at 50\% RH) and $\alpha$-pinene are less efficient. Spruce and $\alpha$ pinene have about the same number efficiency of $1 \mathrm{~cm}^{-3} \mathrm{~s}^{-1}$, however spruce reveals a lower particle formation threshold. Overall, the number efficiencies tend to increase with decreasing thresholds, i.e. the lower the threshold to form new particles the more are formed within the same time. Let's in addition include the growth efficiencies (Table 3). Recall that the GR which entered the growth efficiencies are a measure of the surplus of condensable vapors relative to their equilibrium vapor pressure. The growth efficiency for pine is about the same as for spruce and $\alpha$-pinene, averaging to $0.12 \pm 0.04$. The growth efficiency obtained for birch emissions is a factor of 3 larger. This suggests that upon oxidation the birch emission form very low vapor pressure compounds that promote new particle formation in an early stage and condensation later on. Pine emissions, however, seem to provide only small amounts of very low vapor pressure compounds that support new particle formation, and which are less involved in the condensation process at later stages. Spruce emissions (at 50\% RH) and $\alpha$-pinene produce condensing vapors similar to pine emissions, but significantly less of the very low 
pressure vapors that promote new particle formation. The overall enhanced particle formation potential of the stressed birch supports suggestions by Joutsensaari et al. (2005) that plant stress may be an important factor in the processes of natural new particle formation.

If we refer to the relative emission patterns in Fig. 7, low particle formation thresholds go along with large fractions of OVOC and SQT. Accordingly the number efficiencies follow the same trend. However, considering the absolute concentrations, birch and pine emitted a larger OVOC concentration than spruce, whereas absolute SQT concentrations where about the same for all trees. We take this as an indication that plant-emitted OVOC may play a pivotal role in the process of new particle formation in agreement with the importance of oxygenated organics in nucleation events over boreal forests as recently pointed out by (Laaksonen et al., 2008).

At the moment there is not enough information to sufficiently understand the particle formation process in the reaction chamber on the microphysical level. It could be selfnucleation of VOC oxidation products or activation of preexisting thermodynamically stable clusters (e.g. Kulmala, 2006). We can not exclude beyond doubts that plant-emitted sulfur compounds and thus sulfuric acid may be involved, but their concentration should be below $10 \mathrm{ppt}$. The presence of $\mathrm{SO}_{2}$ would favor large nucleation rates as observed in SOA formation in $\alpha$-pinene ozonolysis (Hoppel et al., 2001). Therefore at the moment the absolute values obtained for the thresholds have only a meaning for the conditions regarding VOC, $\mathrm{OH}, \mathrm{O}_{3} \mathrm{RH}$, and $\mathrm{T}$ of our reaction chamber. However, our results suggest that VOC emissions from birch (stressed), pine, and spruce (at $50 \% \mathrm{RH}$ ) very probably aid the early stages of particle formation better than $\alpha$-pinene. The potential to form new particles results in the series birch (stressed) $>$ pine $>$ spruce $($ at $50 \% \mathrm{RH})>\alpha$-pinene. Studies with pure $\alpha$ pinene therefore will not reflect new particle formation processes in the atmosphere very well.

\subsection{Incremental SOA yields}

As discussed above, the concentrations of MT and SQT in the flow from the plant chamber to the reaction chamber provide a measure of the carbon available for particle formation (hypothetical steady state concentrations of MT+SQT). They further provide a direct measure of the carbon consumed in the oxidation reactions, because the observed steady state concentration of $\mathrm{MT}+\mathrm{SQT}$ in the reaction chamber drops to near zero as soon as the particle formation events are initiated by the $\mathrm{OH}$ radicals. Insofar the slopes of the linear regressions to the $\mathrm{V}_{\operatorname{maxc}}$ vs. ppbC relations in Fig. 8 represent incremental SOA yields in terms of observed volume increase per ppbC consumed. Since we observed particle formation thresholds, the SOA yields are by definition lower than the incremental yields, because one must also consider the threshold amounts of MT+SQT, which were consumed to

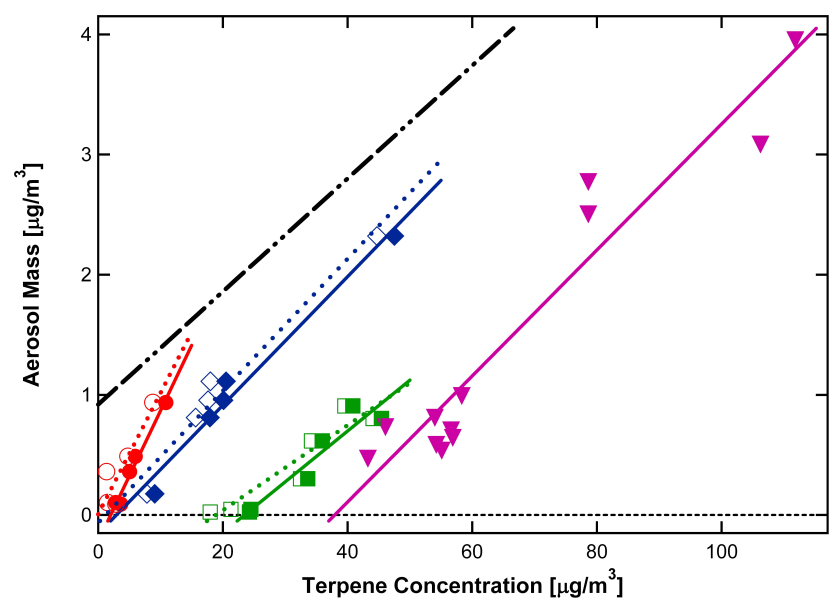

Fig. 10. Aerosol mass concentration as a function of the terpene mass concentration for emissions of birch (red circles), pine (blue diamonds), spruce (green squares), and $\alpha$-pinene (magenta triangles). Filled symbols and solid lines consider mass concentrations of MT+SQT as precursors; open symbols and dotted lines consider mass concentrations of MT only as precursor. The slopes of the lines are the fractional mass yields. The plant chamber data were compared with results of trajectory analysis over boreal forest by Tunved et al. (2008) for the Hyytiälä station (slope $=0.047$, intercept $=0.92 \mu \mathrm{g} \mathrm{m}^{-3}$, double dashed double dotted line). For the conifers and $\alpha$-pinene the mass fractional yields in the plant chamber study agree within $10 \%$ with the analysis of field observations.

provide sufficient supersaturation of vapors to generate and to grow the particles. Nevertheless, the incremental yields are still generally meaningful because (i) they do not depend on the magnitude of VOC consumption as long as the relations remain approximately linear. (ii) Given the linearity over a wide range of the carbon mixing ratio, incremental yields formally give the upper bound of the SOA yields, because with increasing VOC consumption the threshold carbon mixing ratio becomes negligible with respect to the consumed carbon mixing ratio. (iii) To a large extent, incremental yields are independent of the history of the particle ensemble, e.g. if particles were freshly formed or if the vapors condensed on pre-existing seed particles.

For better comparison with the literature, we converted the MT+SQT mixing ratios and the particle volume concentrations to mass concentrations $\left[\mu \mathrm{g} \mathrm{m}^{-3}\right]$, by using the average density of $1.25 \mathrm{~g} \mathrm{~cm}^{-3}$ as determined above. The data sets on mass basis are shown in Fig. 10. From the slopes of the linear regression to the data sets on mass basis it is possible to obtain dimensionless incremental mass yields, which are given in Table 3. For $\alpha$-pinene, we obtained a slope of $0.052 \pm 0.005$, that corresponds to an incremental mass yield of $5.2 \pm 0.5 \%$ (see Sect. 4.1). The corresponding incremental mass yields for SOA formation from pine and spruce emissions were $5.3 \pm 0.5 \%$ and $4.2 \pm 0.7 \%$, respectively (Table 3 ). 
Within the error limits, the incremental mass yields of the VOC emitted by both conifers were the same as for $\alpha$-pinene, on average $4.9 \pm 0.4 \%$. The data for birch showed a larger incremental mass yield of $11 \pm 1 \%$. However, the emission patterns of the birch indicated influence of some stress. The incremental SOA mass yield is thus largest for the (stressed) birch. Pine, spruce, and $\alpha$-pinene have about the same incremental SOA mass yield which is about half of that for the (stressed) birch. With the note that there is a certain natural variability within a tree species, $\alpha$-pinene seems to be a good model compound to predict the incremental volume and mass yields for emissions of coniferous trees, but not for birch, a deciduous tree which in addition was facing some stress.

The derived incremental mass yields should compare with field observations. In Fig. 10 the observed SOA mass concentrations were related also to the MT emissions only (open symbols, dotted lines), because only MT mixing ratios are often available from field studies. The incremental mass yields for MT only are also given in Table 3. They show the same behavior as already discussed in the results Sect. 3 and are somewhat smaller than the MT+SQT case but still the same within the statistical errors. This allows comparisons to data obtained in the real atmosphere where SQT are only rarely measurable.

Tunved et al. (2006, 2008) analyzed air parcel trajectories and correlated the aerosol mass concentration observed at the Hyytiälä station in Finland to the air mass residence time over land in which the aerosols were formed, weighted by the emission strength of MT. Only transport sectors lacking substantial anthropogenic sources were considered. This type of analysis has some similarities with our experiments in the CSTR, where emissions are continuously fed into the "air parcel" and the evolution of the aerosols in time is followed. For comparison we added the relation between mass concentration of MT emissions and integrated aerosol mass as given by Tunved et al. (2008) to Fig. 10. The Tunved et al. (2008) curve shows a positive $\mathrm{y}$-intercept of $0.92 \mu \mathrm{g} \mathrm{m}^{-3}$. This low threshold value is attributed to pre-existing aerosols. Tunved et al. (2008) found a slope of 0.047, which in our terms corresponds to incremental mass yields of $4.7 \%$. This differs less than $10 \%$ from the average result obtained in the chamber for conifers and $\alpha$-pinene.

Considering the different methods used to obtain the data, this is an amazingly good agreement. In turn, the good agreement points out that volume formation efficiencies and incremental mass yields (the slopes of growth curves i.e. curves of SOA volume or mass formed per consumed carbon) have a more general meaning and should be considered besides the classical yield which includes the intercept of the growth curves. Moreover the agreement of our incremental mass yields with Tunved et al. (2008) analysis, indicates that the chamber data are indeed only compressed in the time. So the same emission of carbon generates the same amount of secondary organic particulate mass - once saturation vapor pressures are exceeded - with a caveat that this process will be 10-20 times slower in the atmosphere because of somewhat lower VOC and lower $\mathrm{OH}$ concentrations.

\subsection{Climatic implications}

The observed linear dependence of $\mathrm{V}_{\operatorname{maxc}}$ on the carbon mixing ratio allows for a simplistic prediction for climate change scenarios. For example, in a recent model study, Lathiere et al. (2005) allowed vegetation to adapt to the future climate (year 2100) and predicted an increase of the global MT emissions by up to $50 \%$. The change in emission is driven by temperature-induced increase of MT emissions as well as by increasing mean leaf area indices and spatial extension of the boreal and temperate forests. For demonstration purpose we assume that a future increase of boreal MT emissions by $50 \%$ would translate into a $50 \%$ increase of the MT concentration. By applying the linear relationships derived in this study and by Tunved et al. (2008) a relative increase of MT concentrations by $50 \%$ should directly translate into an incremental increase of SOA mass by $50 \%$ (assuming sufficient precursor and vapor concentration so that condensation can take place). The effect on total aerosol mass is somewhat smaller because of contributions of the pre-existing (nonSOA) aerosols. E.g., the present day average MT concentration in the Finnish boreal forests is about $10 \mu \mathrm{g} \mathrm{m}^{-3}$ (Tunved et al., 2008). If the MT concentration will increase in the future by $50 \%$, the corresponding increase in aerosol mass would be about $17 \%$, applying Tunveds et al. (2008) fractional mass yield of $4.7 \%$ and assuming that the pre-existing fraction of $0.92 \mu \mathrm{g} \mathrm{m}^{-3}$ given by Tunved et al. (2008) still holds for future conditions.

Based on our study we can also construct the present and future scenarios based on tree species. According to Lindfors and Laurila (2000) about $90 \%$ of the MT in the southern boreal forests around Hyytiälä are emitted by pine and spruce and $10 \%$ by deciduous trees, from which birch constitute the overwhelming portion of $75 \%$. For simplicity we again assume that MT emission strength translates one to one in MT concentrations, hence the conifers contribute about $\approx 9 \mu \mathrm{g} \mathrm{m}^{-3}$ and birch (and other deciduous trees) about $\approx 1 \mu \mathrm{g} \mathrm{m}^{-3}$ MT to the current $\approx 10 \mu \mathrm{g} \mathrm{m}^{-3}$ MT concentration. That will lead to a production of $0.45 \mu \mathrm{g} \mathrm{m}^{-3}$ and $0.10 \mu \mathrm{g} \mathrm{m}^{-3}$ SOA mass, respectively, if we apply our incremental mass yields (Table 3 last entree). If we add the contribution of pre-existing aerosols of $0.92 \mu \mathrm{g} \mathrm{m}^{-3}$ (Tunved et al., 2008), we obtain for today's situation an aerosol mass load of $1.47 \mu \mathrm{g} \mathrm{m}^{-3}\left([0.45+0.12+0.92] \mu \mathrm{g} \mathrm{m}^{-3}\right)$, which is only $6 \%$ larger than Tunveds estimate of today's value of about $1.39 \mu \mathrm{g} \mathrm{m}^{-3}$.

A MT increase by $50 \%$ likewise for coniferous trees and birch will lead to $13.5 \mu \mathrm{g} \mathrm{m}^{-3}$ MT originating from pine and spruce and $1.5 \mu \mathrm{g} \mathrm{m}^{-3}$ contributed by birch (and other deciduous trees). According to our plant chamber simulations this will be translated to $0.68 \mu \mathrm{g} \mathrm{m}^{-3} \mathrm{SOA}$ from the conifers and $0.15 \mu \mathrm{g} \mathrm{m}^{-3}$ from birch. If the contribution 
of pre-existing aerosols will not change much in the future, we estimate a future aerosol load of $1.75 \mu \mathrm{g} \mathrm{m}^{-3}$ $\left([0.68+0.15+0.92] \mu \mathrm{g} \mathrm{m}^{-3}\right)$. This would correspond to an increase of the future total aerosol mass by SOA from enhanced boreal VOC emissions of $19 \%$. This is smaller than the $90 \%$ (global) change predicted by Tsigaridis and Kanakidou (2007) based on the same vegetation model used by Lathiere et al. (2005). In our calculation we assumed today's oxidant levels in the future atmosphere which is not what models predict. According to the linearity of our findings higher oxidant levels should lead to the same amount of aerosols per ppbC but faster. Thus enhanced oxidant levels together with enhanced VOC emissions should lead to increased source strength for SOA in the future. It is noted that the above considerations are based on data from a "stressed" birch, but this situation may represent late spring and summer in the south boreal forest.

\section{Summary and conclusions}

This work summarizes results from a comprehensive laboratory study using tree species from the boreal forest as direct source of VOC emission for particle formation induced by photo-oxidation. Experiments were performed in a unique setup that allows studies of aerosol formation from realistic VOC mix emitted by plants. The two chamber setup with independent temperature, light, and RH control enables independent and optimized adjustment of the plants' environment and the conditions in the reaction chamber where particle formation is induced. Most experiments were performed at low VOC level, realistic ozone concentrations, and $\mathrm{OH}$ levels of few times $10^{7} \mathrm{~cm}^{-3}$. The incremental mass yields of $5-10 \%$ provided particle mass in the range of $0.2-2 \mu \mathrm{g} \mathrm{m}^{-3}$, which is realistic for the boreal boundary layer (Allan et al., 2006; Laaksonen et al., 2008; Tunved et al., 2008). It is noted that this particle mass was generated in 10 to 20 fold shorter time than in the real atmosphere.

Our results indicate that it is possible to neglect details of the complex VOC mix emitted. Simplification was achieved by applying the carbon mixing ratio and grouping in compound classes. The total carbon mixing ratio of the emission appears as the most important parameter to predict aerosol number and mass produced for individual tree species.

Compared to $\alpha$-pinene, the tree emissions exhibit lower nucleation thresholds. In addition birch and pine emissions exhibit larger particle formation efficiencies. Thus, we conclude that $\alpha$-pinene may not be a good reference compound for understanding new particle formation from tree emissions, but it is a good model compound to predict the volume or incremental mass yields for coniferous trees. Birch deviates from all other either because it is a deciduous tree or because it faced some stress. It still remains to narrow down the role of stress in case of the birch and the $\mathrm{RH}$ dependence of the particle formation rate in case of the spruce.
A specific contribution of SQT to formation and growth, besides the larger contribution to the carbon mixing ratio per molecule, is not evident from our data. SQT react substantially with $\mathrm{O}_{3}$, and the $\mathrm{SQT}+\mathrm{O}_{3}$ reactions do not induce particle formation events. Since the VOC levels in this study where somewhat high and the oxidation chemistry was accelerated compared to atmospheric conditions, the absence of particle formation events in absence of photochemical $\mathrm{OH}$ production suggest limited importance of direct ozonolysis for new particle formation in the atmosphere.

While particle growth and volume formation is dominated by $\mathrm{OH}$ oxidation of MT, OVOC oxidation could play a certain role in natural nucleation processes. Particle formation thresholds are lower and particle formation rates are higher at larger OVOC fraction. Since the role and fraction of OVOC in plant emissions is yet not understood, their possible importance for aerosol nucleation and growth can be well studied using real plants as emitters. This further emphasizes the need of this type of integral simulation experiments.

The incremental mass yields of $5 \%$ for conifers and $\alpha$ pinene (Table 3, last entry) agree well with field-derived yields of $4.7 \%$ derived by Tunved et al. (2008). This clearly points to the general significance of incremental mass yields which describe the amount of SOA mass formed per consumed VOC in presence of other, either freshly formed or pre-existing, aerosols. Using the derived incremental mass yields we predict that an increase in MT (and SQT) emissions in a future climate would yield an aerosol mass increase of about $17 \%$ for a predicted $50 \%$ increase of the MT concentration the southern boreal region.

Acknowledgements. We gratefully acknowledge the support by the European Commission (IP-EUCAARI, Contract No. 036833-2, and NoE-ACCENT) and by the ESF (INTROP). YR acknowledges support by the Helen and Martin Kimmel Award for Innovative Investigation and the Israel Science Foundation (grants 196/08).

Edited by: A. Wiedensohler

\section{References}

Allan, J. D., Alfarra, M. R., Bower, K. N., Coe, H., Jayne, J. T., Worsnop, D. R., Aalto, P. P., Kulmala, M., Hyotylainen, T., Cavalli, F., and Laaksonen, A.: Size and composition measurements of background aerosol and new particle growth in a Finnish forest during QUEST 2 using an Aerodyne aerosol mass spectrometer, Atmos. Chem. Phys., 6, 315-327, 2006,

http://www.atmos-chem-phys.net/6/315/2006/.

Atkinson, R. and Arey, J.: Gas-phase tropospheric chemistry of biogenic volatile organic compounds: A review, Atmos. Environ., 37, S197-S219, 2003.

Atkinson, R. and Aschmann, S. M.: OH radical production from the gas-phase reactions of $\mathrm{O}_{3}$ with a series of alkenes under atmospheric conditions, Environ. Sci. Technol., 27, 1357-1363, 1993.

Bahreini, R., Keywood, M. D., Ng, N. L., Varutbangkul, V., Gao, S., Flagan, R. C., Seinfeld, J. H., Worsnop, D. R. and Jimenez, J. L.: 
Measurements of secondary organic aerosol from oxidation of cycloalkenes, terpenes, and m-xylene using an Aerodyne aerosol mass spectrometer, Environ. Sci. Technol., 39, 5674-5688, 2005.

Barth, M., McFadden, J. P., Sun, J., Wiedinmyer, C., Chuang, P., Collins, D., Griffin, R., Hannigan, M., Karl, T., Kim, S.-W., Lasher-Trapp, S., Levis, S., Litvak, M., Mahowald, N., Moore, K., S., N., Nemitz, E., Nenes, A., Potosnak, M., Raymond, T. M., Smith, J., Still, C., and Stroud, C.: Coupling between land ecosystems and the atmospheric hydrologic cycle through biogenic aerosol pathways, B. Am. Meteorol. S., 1738-1742, 2005.

Bilde, M., Svenningsson, B., Monster, J., and Rosenorn, T.: Evenodd alternation of evaporation rates and vapor pressures of $\mathrm{C}_{3}$ $\mathrm{C}_{9}$ dicarboxylic acid aerosols, Environ. Sci. Technol., 37, 13711378, 2003.

Bonn, B., Kulmala, M., Riipinen, I., Sihto, S. L., and Ruuskanen, T. M.: How biogenic terpenes govern the correlation between sulfuric acid concentrations and new particle formation, J. Geophys. Res.-Atmos., 113, 2008.

Bonn, B. and Moortgat, G. K.: New particle formation during alpha- and beta-pinene oxidation by $\mathrm{O}_{3}, \mathrm{OH}$ and $\mathrm{NO}_{3}$, and the influence of water vapour: Particle size distribution studies, Atmos. Chem. Phys., 2, 183-196, 2002, http://www.atmos-chem-phys.net/2/183/2002/.

Bonn, B. and Moortgat, G. K.: Sesquiterpene ozonolysis: Origin of atmospheric new particle formation from biogenic hydrocarbons, Geophys. Res. Lett., 30, 1585, doi:10.1029/2003GL017000, 2003

Boy, M., Kulmala, M., Ruuskanen, T. M., Pihlatie, M., Reissell, A., Aalto, P. P., Keronen, P., Dal Maso, M., Hellen, H., Hakola, H., Jansson, R., Hanke, M., and Arnold, F.: Sulphuric acid closure and contribution to nucleation mode particle growth, Atmos. Chem. Phys., 5, 863-878, 2005, http://www.atmos-chem-phys.net/5/863/2005/.

Calogirou, A., Larsen, B. R. and Kotzias, D.: Gas-phase terpene oxidation products: A review, Atmos. Environ., 33, 1423-1439, 1999.

Carrasco, N., Doussin, J. F., O'Connor, M., Wenger, J. C., PicquetVarrault, B., Durand-Jolibois, R., and Carlier, P.: Simulation chamber studies of the atmospheric oxidation of 2-methyl-3buten-2-ol: Reaction with hydroxyl radicals and ozone under a variety of conditions, J. Atmos. Chem., 56, 33-55, 2007.

Ciccioli, P., Brancaleoni, E., Frattoni, M., Cecinato, A., and Brachetti, A.: Ubiquitous occurrence of semivolatile carbonylcompounds in tropospheric samples and their possible sources, Atmos. Environ., 27, 1891-1901, 1993.

Cocker, D. R., Clegg, S. L., Flagan, R. C. and Seinfeld, J. H.: The effect of water on gas-particle partitioning of secondary organic aerosol. Part I: alpha-pinene/ozone system, Atmos. Environ., 35, 6049-6072, 2001.

Croft, K. P. C., Juttner, F., and Slusarenko, A. J.: Volatile products of the lipoxygenase pathway evolved from phaseolus-vulgaris (1) leaves inoculated with pseudomonas-syringae pv-phaseolicola, Plant Physiol., 101, 13-24, 1993.

DeCarlo, P. F., Slowik, J. G., Worsnop, D. R., Davidovits, P. and Jimenez, J. L.: Particle morphology and density characterization by combined mobility and aerodynamic diameter measurements. Part 1: Theory, Aerosol. Sci. Tech., 38, 1185-1205, 2004.

Denman, K. L., Brasseur, G., Chidthaisong, A., Ciais, P., Cox, P. M., Dickinson, R. E., Hauglustaine, D., Heinze, C., Holland, E.,
Jacob, D., Lohmann, U., Ramachandran, S., da Silva Dias, P. L., Wofsy, S. C., and Zhang, X., Couplings between changes in the climate system and biogeochemistry, in: Climate change 2007: The physical science basis. Contribution of working group i to the fourth assessment report of the intergovernmental panel on climate change, edited by: Solomon, S., Qin, D., Manning, M., Chen, Z., Marquis, M., Averyt, K. B., Tignor, M., and Miller, H. L., Cambridge University Press, Cambridge, New York, 2007.

Donahue, N. M., Robinson, A. L., Stanier, C. O., and Pandis, S. N.: Coupled partitioning, dilution, and chemical aging of semivolatile organics, Environ. Sci. Technol., 40, 2635-2643, 2006.

Folkers, A.: Sauerstoffhaltige flüchtige organische Verbindungen in der Troposphäre: Entwicklung und Anwendung einer gaschromatographischen Nachweismethode, Universität zu Köln, Köln, 2002.

Folkers, A., Hüve, K., Ammann, C., Dindorf, T., Kesselmeier, J., Kleist, E., Kuhn, U., Uerlings, R. and Wildt, J.: Methanol emissions from deciduous tree species: dependence on temperature and light intensity, Plant Biol., 10, 65-75, 2008.

Fu, T. M., Jacob, D. J., Wittrock, F., Burrows, J. P., Vrekoussis, M., and Henze, D. K.: Global budgets of atmospheric glyoxal and methylglyoxal, and implications for formation of secondary organic aerosols, J. Geophys. Res., 113, D15303, doi:10.1029/2007JD009505, 2008.

Haapanala, S., Rinne, J., Hakola, H., Hellen, H., Laakso, L., Lihavainen, H., Janson, R., O'Dowd, C., and Kulmala, M.: Boundary layer concentrations and landscape scale emissions of volatile organic compounds in early spring, Atmos. Chem. Phys., 7, 1869-1878, 2007, http://www.atmos-chem-phys.net/7/1869/2007/.

Hakola, H., Tarvainen, V., Laurila, T., Hiltunen, V., Hellen, H., and Keronen, P.: Seasonal variation of voc concentrations above a boreal coniferous forest, Atmos. Environ., 37, 1623-1634, 2003.

Hari, P., Raivonen, M., Vesala, T., Munger, J. W., Pilegaard, K., and Kulmala, M.: Atmospheric science - Ultraviolet light and leaf emission of NOx, Nature, 422, 134-134, 2003.

Heald, C. L., Jacob, D. J., Park, R. J., Russell, L. M., Huebert, B. J., Seinfeld, J. H., Liao, H., and Weber, R. J.: A large organic aerosol source in the free troposphere missing from current models, Geophys. Res. Lett., 32, L18809, doi:10.1029/2005GL023831, 2005 .

Healy, R. M., Wenger, J. C., Metzger, A., Duplissy, J., Kalberer, M., and Dommen, J.: Gas/particle partitioning of carbonyls in the photooxidation of isoprene and 1,3,5-trimethylbenzene, Atmos. Chem. Phys., 8, 3215-3230, 2008, http://www.atmos-chem-phys.net/8/3215/2008/.

Heiden, A. C., Hoffmann, T., Kahl, J., Kley, D., Klockow, D., Langebartels, C., Mehlhorn, H., Sandermann, H., Schraudner, M., Schuh, G., and Wildt, J.: Emission of volatile organic compounds from ozone-exposed plants, Ecol. Appl., 9, 1160-1167, 1999.

Heiden, A. C., Kobel, K., Langebartels, C., Schuh-Thomas, G., and Wildt, J.: Emissions of oxygenated volatile organic compounds from plants - part I: Emissions from lipoxygenase activity, J. Atmos. Chem., 45, 143-172, 2003.

Hoppel, W., Fitzgerald, J., Frick, G., Caffrey, P., Pasternack, L., Hegg, D., Gao, S., Leaitch, R., Shantz, N., Cantrell, C., Albrechcinski, T., Ambrusko, J., and Sullivan, W.: Particle 
formation and growth from ozonolysis of a-pinene, J. Geophys. Res., 106, 27603-27618, 2001.

Hüve, K., Christ, M. M., Kleist, E., Uerlings, R., Niinemets, U., Walter, A., and Wildt, J.: Simultaneous growth and emission measurements demonstrate an interactive control of methanol release by leaf expansion and stomata, J. Exp Bot., 58, 1783-1793, 2007.

Jayne, J. T., Leard, D. C., Zhang, X. F., Davidovits, P., Smith, K. A., Kolb, C. E., and Worsnop, D. R.: Development of an aerosol mass spectrometer for size and composition analysis of submicron particles, Aerosol. Sci. Tech., 33, 49-70, 2000.

Joutsensaari, J., Loivamaki, M., Vuorinen, T., Miettinen, P., Nerg, A. M., Holopainen, J. K., and Laaksonen, A.: Nanoparticle formation by ozonolysis of inducible plant volatiles, Atmos. Chem. Phys., 5, 1489-1495, 2005,

http://www.atmos-chem-phys.net/5/1489/2005/.

Kerminen, V. M., Lihavainen, H., Komppula, M., Viisanen, Y., and Kulmala, M.: Direct observational evidence linking atmospheric aerosol formation and cloud droplet activation, Geophys. Res. Lett., 32, L14803, doi:10.1029/2005GL023130,2005.

Koponen, I. K., Riipinen, I., Hienola, A., Kulmala, M., and Bilde, M.: Thermodynamic properties of malonic, succinic, and glutaric acids: Evaporation rates and saturation vapor pressures, Environ. Sci. Technol., 41, 3926-3933, 2007.

Korhonen, H., Lehtinen, K. E. J., Pirjola, L., Napari, I., Vehkamaki, H., Noppel, M., and Kulmala, M.: Simulation of atmospheric nucleation mode: A comparison of nucleation models and size distribution representations, J. Geophys. Res., 108, 4471, doi:10.1029/2002JD003305, 2003.

Kostenidou, E., Pathak, R. K. and Pandis, S. N.: An algorithm for the calculation of secondary organic aerosol density combining ams and smps data, Aerosol. Sci. Tech., 41, 1002-1010, 2007.

Kroll, J. H. and Seinfeld, J. H.: Chemistry of secondary organic aerosol: Formation and evolution of low-volatility organics in the atmosphere, Atmos. Environ., 42, 3593-3624, 2008.

Kuhn, U., Andreae, M. O., Ammann, C., Araujo, A. C., Brancaleoni, E., Ciccioli, P., Dindorf, T., Frattoni, M., Gatti, L. V., Ganzeveld, L., Kruijt, B., Lelieveld, J., Lloyd, J., Meixner, F. X., Nobre, A. D., Poschl, U., Spirig, C., Stefani, P., Thielmann, A., Valentini, R., and Kesselmeier, J.: Isoprene and monoterpene fluxes from central amazonian rainforest inferred from towerbased and airborne measurements, and implications on the atmospheric chemistry and the local carbon budget, Atmos. Chem. Phys., 7, 2855-2879, 2007,

http://www.atmos-chem-phys.net/7/2855/2007/.

Kulmala, M.: How particles nucleate and grow, Science, 302, 1000 1001, 2003.

Kulmala, M., Dal Maso, M., Makela, J. M., Pirjola, L., Vakeva, M., Aalto, P., Miikkulainen, P., Hameri, K., and O'Dowd, C. D.: On the formation, growth and composition of nucleation mode particles, Tellus B, 53, 479-490, 2001.

Kulmala, M., Lehtinen, K. E. J., and Laaksonen, A.: Cluster activation theory as an explanation of the linear dependence between formation rate of $3 \mathrm{~nm}$ particles and sulphuric acid concentration, Atmos. Chem. Phys., 6, 787-793, 2006, http://www.atmos-chem-phys.net/6/787/2006/.

Kulmala, M., Riipinen, I., Sipila, M., Manninen, H. E., Petaja, T., Junninen, H., Dal Maso, M., Mordas, G., Mirme, A., Vana, M., Hirsikko, A., Laakso, L., Harrison, R. M., Hanson, I., Leung, C.,
Lehtinen, K. E. J., and Kerminen, V. M.: Toward direct measurement of atmospheric nucleation, Science, 318, 89-92, 2007.

Kulmala, M., Suni, T., Lehtinen, K. E. J., Dal Maso, M., Boy, M., Reissell, A., Rannik, U., Aalto, P., Keronen, P., Hakola, H., Back, J. B., Hoffmann, T., Vesala, T., and Hari, P.: A new feedback mechanism linking forests, aerosols, and climate, Atmos. Chem. Phys., 4, 557-562, 2004a,

http://www.atmos-chem-phys.net/4/557/2004/.

Kulmala, M., Vehkamaki, H., Petajda, T., Dal Maso, M., Lauri, A., Kerminen, V. M., Birmili, W., and McMurry, P. H.: Formation and growth rates of ultrafine atmospheric particles: A review of observations, J. Aerosol Sci., 35, 143-176, 2004b.

Laaksonen, A., Kulmala, M., O’Dowd, C. D., Joutsensaari, J., Vaattovaara, P., Mikkonen, S., Lehtinen, K. E. J., Sogacheva, L., Dal Maso, M., Aalto, P., Petaja, T., Sogachev, A., Yoon, Y. J., Lihavainen, H., Nilsson, D., Facchini, M. C., Cavalli, F., Fuzzi, S., Hoffmann, T., Arnold, F., Hanke, M., Sellegri, K., Umann, B., Junkermann, W., Coe, H., Allan, J. D., Alfarra, M. R., Worsnop, D. R., Riekkola, M. L., Hyotylainen, T., and Viisanen, Y.: The role of VOC oxidation products in continental new particle formation, Atmos. Chem. Phys., 8, 2657-2665, 2008, http://www.atmos-chem-phys.net/8/2657/2008/.

Lathiere, J., Hauglustaine, D. A., De Noblet-Ducoudre, N., Krinner, G., and Folberth, G. A.: Past and future changes in biogenic volatile organic compound emissions simulated with a global dynamic vegetation model, Geophys. Res. Lett., 32, L20818, doi:10.1029/2005GL024164, 2005.

Lindfors, V. and Laurila, T.: Biogenic volatile organic compound (VOC) emissions from forests in Finland, Boreal Environ. Res., 5, 95-113, 2000.

Lyubovtseva, Y. S., Sogacheva, L., Dal Maso, M., Bonn, B., Keronen, P. and Kulmala, M.: Seasonal variations of trace gases, meteorological parameters, and formation of aerosols in boreal forest, Boreal Environ. Res., 10, 493-510, 2005.

McFiggans, G., Coe, H., Burgess, R., Allan, J., Cubison, M., Alfarra, M. R., Saunders, R., Saiz-Lopez, A., Plane, J. M. C., Wevill, D. J., Carpenter, L. J., Rickard, A. R. and Monks, P. S.: Direct evidence for coastal iodine particles from laminaria macroalgae - linkage to emissions of molecular iodine, Atmos. Chem. Phys., 4, 701-713, 2004, http://www.atmos-chem-phys.net/4/701/2004/.

Ng, N. L., Kroll, J. H., Keywood, M. D., Bahreini, R., Varutbangkul, V., Flagan, R. C., Seinfeld, J. H., Lee, A., and Goldstein, A. H.: Contribution of first- versus second-generation products to secondary organic aerosols formed in the oxidation of biogenic hydrocarbons, Environ. Sci. Technol., 40, 2283-2297, 2006.

Pathak, R. K., Presto, A. A., Lane, T. E., Stanier, C. O., Donahue, N. M., and Pandis, S. N.: Ozonolysis of alpha-pinene: Parameterization of secondary organic aerosol mass fraction, Atmos. Chem. Phys., 7, 3811-3821, 2007a, http://www.atmos-chem-phys.net/7/3811/2007/.

Pathak, R. K., Stanier, C. O., Donahue, N. M., and Pandis, S. N.: Ozonolysis of alpha-pinene at atmospherically relevant concentrations: Temperature dependence of aerosol mass fractions (yields), J. Geophys. Res., 112, D03201, doi:10.1029/2006JD007436, 2007b.

Paulson, S. E., Chung, M., Sen, A. D., and Orzechowska, G.: Measurement of $\mathrm{OH}$ radical formation from the reaction of ozone 
with several biogenic alkenes, J. Geophys. Res., 103, 2553325539, 1998.

Paulson, S. E., Flagan, R. C., and Seinfeld, J. H.: Atmospheric photooxidation of isoprene. 2. The ozone-isoprene reaction, Int. J. Chem. Kinet., 24, 103-125, 1992.

Pinto, D. M., Tiiva, P., Miettinen, P., Joutsensaari, J., Kokkola, H., Nerg, A. M., Laaksonen, A., and Holopainen, J. K.: The effects of increasing atmospheric ozone on biogenic monoterpene profiles and the formation of secondary aerosols, Atmos. Environ., 41, 4877-4887, 2007.

Rudich, Y., Donahue, N. M., and Mentel, T. F.: Aging of organic aerosol: Bridging the gap between laboratory and field studies, Annu. Rev. Phys. Chem., 58, 321-352, 2007.

Saathoff, H., Naumann, K.-H., Mhler, O., Jonsson, Å. M., Hallquist, M., Kiendler-Scharr, A., Mentel, Th. F., Tillmann, R., and Schurath, U.: Temperature dependence of yields of secondary organic aerosols from the ozonolysis of ?-pinene and limonene, Atmos. Chem. Phys., 9, 1551-1577, 2009, http://www.atmos-chem-phys.net/9/1551/2009/.

Schimang, R., Folkers, A., Kleffmann, J., Kleist, E., Miebach, M., and Wildt, J.: Uptake of gaseous nitrous acid (HONO) by several plant species, Atmos. Environ., 40, 1324-1335, 2006.

Schuh, G., Heiden, A. C., Hoffmann, T., Kahl, J., Rockel, P., Rudolph, J., and Wildt, J.: Emissions of volatile organic compounds from sunflower and beech: Dependence on temperature and light intensity, J. Atmos. Chem., 27, 291-318, 1997.

Seco, R., Penuelas, J., and Filella, I.: Short-chain oxygenated VOCs: Emission and uptake by plants and atmospheric sources, sinks, and concentrations, Atmos. Environ., 41, 2477-2499, 2007.

Spirig, C., Neftel, A., Ammann, C., Dommen, J., Grabmer, W., Thielmann, A., Schaub, A., Beauchamp, J., Wisthaler, A., and Hansel, A.: Eddy covariance flux measurements of biogenic VOCs during echo 2003 using proton transfer reaction mass spectrometry, Atmos. Chem. Phys., 5, 465-481, 2005, http://www.atmos-chem-phys.net/5/465/2005/.

Tarvainen, V., Hakola, H., Rinne, J., Hellen, H., and Haapanala, S.: Towards a comprehensive emission inventory of terpenoids from boreal ecosystems, Tellus B, 59, 526-534, 2007.
Tillmann, R., Hallquist, M., Iinuma, Y., Jonsson, A. M., KiendlerScharr, A., Saathoff, H., and Mentel, T. F.: Water and temperature dependence of pinonaldehyde and $\mathrm{OH}$ yields from ozonolyis of a-pinene, in preparation, 2009.

Tsigaridis, K. and Kanakidou, M.: Secondary organic aerosol importance in the future atmosphere, Atmos. Environ., 41, 46824692, 2007.

Tunved, P., Hansson, H. C., Kerminen, V. M., Strom, J., Dal Maso, M., Lihavainen, H., Viisanen, Y., Aalto, P. P., Komppula, M., and Kulmala, M.: High natural aerosol loading over boreal forests, Science, 312, 261-263, 2006.

Tunved, P., Stroem, J., Kulmala, M., Kerminen, V.-M., Dal Maso, M., Svenningson, B., Lunder, C., and Hansson, H.-C.: The natural aerosol over northern europe and its relation to anthropogenic emissions-implications of important climate feedbacks, Tellus B, 60, 473-484, 2008.

Van Reken, T. M., Greenberg, J. P., Harley, P. C., Guenther, A. B., and Smith, J. N.: Direct measurement of particle formation and growth from the oxidation of biogenic emissions, Atmos. Chem. Phys., 6, 4403-4413, 2006, http://www.atmos-chem-phys.net/6/4403/2006/.

Volkamer, R., Jimenez, J. L., San Martini, F., Dzepina, K., Zhang, Q., Salcedo, D., Molina, L. T., Worsnop, D. R., and Molina, M. J.: Secondary organic aerosol formation from anthropogenic air pollution: Rapid and higher than expected, Geophys. Res. Lett., 33, L17811, doi:10.1029/2006GL026899, 2006.

Went, F. W.: Blue hazes in the atmosphere, Nature, 187, 641-643, 1960.

Wildt, J., Kley, D., Rockel, A., Rockel, P., and Segschneider, H. J.: Emission of NO from several higher plant species, J. Geophys. Res., 102, 5919-5927, 1997.

Wildt, J., Kobel, K., Schuh-Thomas, G., and Heiden, A. C.: Emissions of oxygenated volatile organic compounds from plants part ii: Emissions of saturated aldehydes, J. Atmos. Chem., 45, 173-196, 2003. 